\title{
Extrações dentárias em Ortodontia: avaliação de elementos de diagnóstico
}

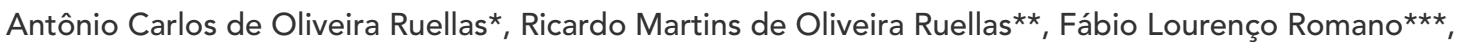 \\ Matheus Melo Pithon**, Rogério Lacerda dos Santos**
}

\section{Resumo}

Algumas más oclusões exigem do ortodontista capacidade de diagnóstico para decidir pela melhor maneira de tratar o paciente. O objetivo dos autores deste artigo foi apresentar casos clínicos e discutir alguns elementos de diagnóstico utilizados na elaboração do plano de tratamento, auxiliando na decisão de extrair dentes. Foi dada ênfase em cada elemento de diagnóstico: aspectos relacionados à cooperação, discrepância de modelo, discrepância cefalométrica e perfil facial, idade esquelética (crescimento) e relações anteroposteriores, assimetrias dentárias, padrão facial e patologias. Sugere-se que a associação dos aspectos citados é importante para a decisão correta. Todavia, algumas vezes, uma característica, por si só, pode definir o plano de tratamento.

Palavras-chave: Ortodontia corretiva. Diagnóstico. Extração dentária. Planejamento ortodôntico.

\section{INTRODUÇÃO}

Desde os primórdios da Ortodontia discutese sobre a necessidade de extrações dentárias em algumas situações ortodônticas. Angle, no início do século XX, defendeu o tratamento ortodôntico sem extrações baseando-se no conceito da linha de oclusão ${ }^{23}$. Segundo o autor, havia potencial para que os 32 dentes se posicionassem corretamente na arcada dentária e, quando isso acontecia, os tecidos adjacentes (tegumento, osso e músculo) se adaptavam a essa nova posição. Pensando dessa forma, ensinou aos seus alunos e tratou inúmeros casos $^{24}$.

Um dos maiores opositores de Angle foi Calvin Case, que defendia o tratamento ortodôntico com extrações em alguns casos. Relatava que extrações dentárias nunca deveriam ser realizadas com a finalidade de facilitar a mecânica ortodôntica, mas para propiciar o melhor tratamento ao paciente ${ }^{2}$.

Tweed, um dos mais brilhantes alunos da escola de Angle, durante muitos anos seguiu fielmente os conceitos de seu mestre, realizando tratamentos sem extrações dentárias. Como clínico criterioso, observou que muitos de seus casos recidivaram, principalmente aqueles em que os incisivos inferiores não terminavam em posição vertical em relação à base óssea. Dessa forma, retratou pacientes com extrações de quatro pré-molares e obteve melhores resultados estéticos e funcionais. De seguidor fiel, Tweed

* Doutor em Ortodontia pela Universidade Federal do Rio de Janeiro (UFRJ). Professor Associado de Ortodontia da Universidade Federal

do Rio de Janeiro (UFRJ).

** Mestre em Ortodontia pela Universidade Federal do Rio de Janeiro (UFRJ).

*** Doutor em Ortodontia pela Universidade Estadual de Campinas (UNICAMP). Professor Doutor de Ortodontia da Faculdade de Odontologia de Ribeirão Preto, Universidade de São Paulo (USP). 
tornou-se opositor das ideias não-extracionistas de Angle, motivo pelo qual foi criticado pelos ortodontistas da época ${ }^{23}$.

Essa dicotomia permanece até os dias atuais: o diagnóstico de algumas más oclusões deixa dúvidas quanto à realização de extrações. Segundo Dewel ${ }^{7}$, o desafio do diagnóstico ortodôntico não está naqueles casos que declaradamente requerem extrações ou naqueles que não as necessitam, mas, sim, num extenso grupo conhecido como casos limítrofes. Não há, na literatura, unanimidade em relação ao valor da discrepância negativa na arcada inferior que caracterize tais casos. Entretanto, aceitam-se variações entre -3 e $-6 \mathrm{~mm}$, de discrepância total, para classificar o caso como limítrofe. Keedy ${ }^{11}$ comentou que o diagnóstico será ditado pela tensão da musculatura e estabilidade pós-tratamento. Williams ${ }^{26}$ observou que, na maioria dos casos limítrofes, o paciente apresenta padrão esquelético adequado e aceitável equilíbrio dos tecidos moles, com a frequência de indicação pelas extrações variando de 5 a $87 \%$ dos casos, por diferentes profissionais.

Diante de qualquer má oclusão, e principalmente de um caso limítrofe, é necessário avaliar as características dentárias, faciais e esqueléticas do paciente para se ter um correto diagnóstico e eficiente plano de tratamento. No presente artigo, serão discutidas algumas dessas características, consideradas elementos de diagnóstico, que devem ser observadas atentamente na decisão sobre a realização de extrações no planejamento do tratamento ortodôntico.

A decisão sobre extrações dentárias vai além da necessidade de obter espaços na arcada, seja para alinhar dentes ou retrair dentes anteriores. Algumas vezes, a extração para alinhar dentes pode comprometer a estética facial, tornando o perfil mais côncavo. Entretanto, obter espaço à custa de movimento distal de dentes posteriores pode também comprometer a estética, tornando o terço inferior mais longo, o que pode resultar em dificuldade de selamento labial. Foram propostos sete itens para serem avaliados como auxiliares nessa decisão e que serviram como guias qualitativos. Ou seja, isso não significa que seis itens favoráveis à extração determinem a sua realização, há casos em que apenas um item pode ser determinante para a decisão.

\section{COOPERAÇÃO}

Todo tratamento ortodôntico necessita de colaboração do paciente como, por exemplo, manter uma higiene bucal adequada, não quebrar ou danificar os acessórios ortodônticos ou, simplesmente, comparecer regularmente às consultas. Porém, para determinados tipos de má oclusão, necessita-se de colaboração adicional para que o tratamento seja executado com sucesso. Para a correção de certos tipos de má oclusão de Classe II, principalmente as de origem esquelética, é necessário o uso de aparelho extrabucal. Também no tratamento de má oclusão de Classe III com deficiência maxilar (paciente com potencial de crescimento), o uso da máscara facial para protração maxilar é um dos tratamentos indicados ${ }^{18}$. É necessário, em grande parte dos tratamentos, o uso de elásticos intermaxilares como auxiliar na correção da má oclusão ou na fase final do tratamento, para intercuspidação, os quais também exigem empenho do paciente em seu uso regular. Todos os recursos citados acima, devido ao comprometimento estético, oferecem dificuldades quanto à aceitação e uso por parte dos pacientes.

É extremamente difícil saber, inicialmente, se o paciente será ou não colaborador, mas através da observação de alguns critérios - como o comportamento do paciente no consultório, o tipo de relacionamento do mesmo com o acompanhante e através de entrevista separada com os pais pode-se arriscar alguma previsão sobre a cooperação. Essas observações aplicam-se, principalmente, ao paciente adolescente. De modo geral, o paciente adulto é mais colaborador do que o jovem, pois é mais maduro emocionalmente para 
entender a importância desse fator em seu tratamento. Quando é necessária uma grande colaboração, sugere-se planejar um reestudo depois de determinado período de tempo, pois, diante da incerteza da efetiva colaboração, o ortodontista não pode contar plenamente com esse fator na resolução dos casos limítrofes.

Algumas vezes, a falta de cooperação prolonga o tempo de tratamento e pode, até mesmo, acarretar em alteração do planejamento inicial, requerendo extrações dentárias.

Más oclusões de Classe II dentárias, com boa arcada inferior, podem ser corrigidas por movimento distal dos dentes superiores com uso de elásticos, ou aparelho extrabucal, o que requer muita cooperação do paciente. Alternativamente, pode-se realizar o movimento distal apoiado em mini-implantes; ou fazer a correção com extrações de pré-molares superiores, exigindo um menor grau de colaboração do paciente.

Alguns tratamentos podem obter resultados semelhantes se conduzidos com ou sem extrações (principalmente casos limítrofes). Entretanto, outros podem ter seu resultado comprometido caso o planejamento tenha sido baseado em mecânicas que dependam de cooperação e o paciente não corresponda.

\section{DISCREPÂNCIA DE MODELO}

A discrepância de modelo deve ser avaliada tanto na arcada superior quanto na inferior. Mas, para fins de diagnóstico, a arcada inferior é prioridade, devido à maior dificuldade em se obter espaço.

Quando o ortodontista se depara com uma discrepância de modelo (DM) negativa acentuada na arcada inferior, dificilmente consegue tratar o paciente sem extrações dentárias. Para pequenas discrepâncias negativas, em grande parte dos casos, o tratamento é realizado sem extrações. Assim, o espaço pode ser obtido por aproveitamento do leeway space (quando ainda for possível), stripping, correção de inclinações acentuadas para mesial dos dentes posteriores inferiores e pequenas expansões e/ou projeções com objetivo de restabelecer inclinações normais aos dentes inferiores, principalmente se acompanhadas por disjunção maxilar.

O caso clínico 1 ilustra a situação de aproveitamento do leeway space para evitar as extrações. A paciente, com 9 anos de idade, possuía discrepância negativa nas arcadas superior e inferior (Fig. 1). Para resolução desse caso, poderia-se optar por extrações dentárias de pré-molares superiores e inferiores. Apesar do perfil ter se mostrado levemente convexo, optou-se pelo tratamento com o aproveitamento do leeway space na arcada inferior e colocação de arco lingual durante a fase de dentição mista (Fig. 1G), além do procedimento de expansão rápida da maxila. Com essa terapêutica, conseguiu-se o alinhamento dentário sem a necessidade de realização de extrações e obteve-se perfil reto que, provavelmente, estaria em pior conformação se o caso tivesse sido tratado com extrações dentárias (Fig. 2, 3).

Outra situação, nos casos de discrepâncias negativas, é aquela onde há necessidade de se realizar extrações dentárias porém não se pode alterar o perfil facial. No caso clínico 2, a paciente possuía perfil facial reto com discrepância negativa nas arcadas superior e inferior e assimetria na arcada inferior (Fig. 4) com desvio da linha média inferior para a direita. Para resolução desse caso, optou-se pelas extrações de três pré-molares (14, 24 e 34). Para evitar retrações excessivas dos dentes anteriores para lingual e aprofundamento do perfil, utilizou-se torque resistente nas arcadas superior e inferior durante a retração dentária, evitando-se verticalização dos incisivos. $\mathrm{O}$ resultado, ao final do tratamento, foi de harmonização dentária no espaço presente, com manutenção do perfil facial (Fig. 5).

Nas discrepâncias de modelo nulas ou positivas, o tratamento é realizado sem extrações, a não ser que o paciente apresente outro problema associado que as indique. 
Proffit e Fields ${ }^{16}$ elaboraram um guia de procedimentos contemporâneos para avaliação de extrações em casos de Classe I com apinhamento e/ou protrusão. Os autores relataram que, em discrepâncias negativas na arcada inferior menores do que $4 \mathrm{~mm}$, raramente a exodontia é necessária, exceto nos casos de protrusão de incisivos ou discrepância vertical posterior. Em discrepâncias negativas na arcada inferior entre 5 e $9 \mathrm{~mm}$, pode-se realizar o tratamento com ou sem extrações, dependendo das características do paciente e da mecanoterapia ortodôntica utilizada. Finalmente, para discrepâncias negativas superiores a $10 \mathrm{~mm}$, a extração é quase sempre necessária, preferindo-se os primeiros pré-molares, pois a extração dos segundos pré-molares não é adequada para grandes discrepâncias.

Ao se decidir resolver a DM com extrações, considerações a respeito de alterações no perfil, por retrações dos dentes anteriores e provável diminuição do terço inferior da face, devem ser realizadas. Porém, quando se decide solucionar a DM negativa sem extrações, considerações devem ser feitas em relação ao provável aumento do terço inferior da face pelo movimento distal de dentes posteriores para se obter espaço. Ou seja, há implicação direta desses mecanismos com o padrão facial, item que será discutido mais adiante.
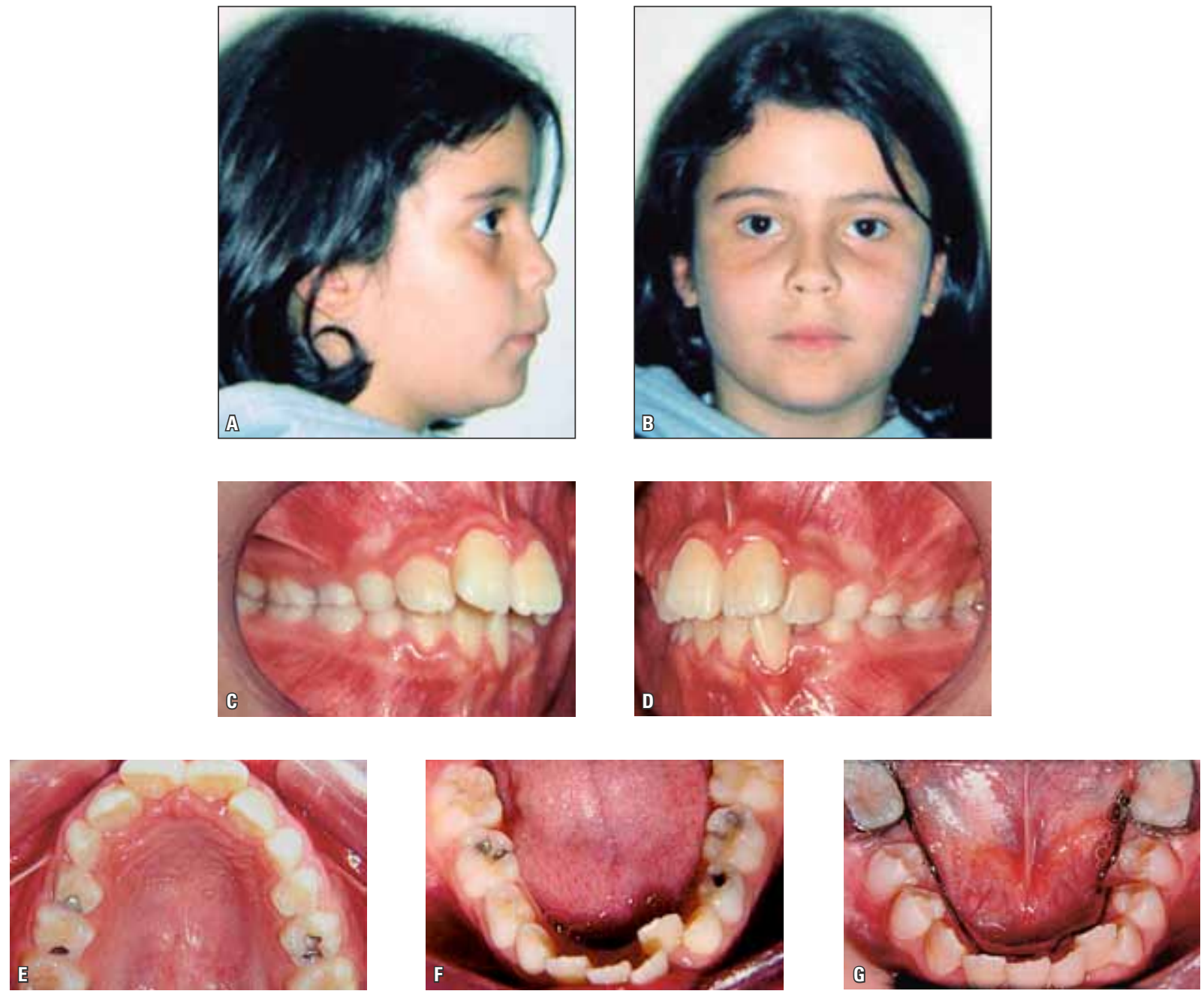

FIGURA 1 - Caso clínico 1. Fotografias iniciais faciais (A, B) e intrabucais (C a F). G) Arco lingual instalado para aproveitamento do leeway space. 

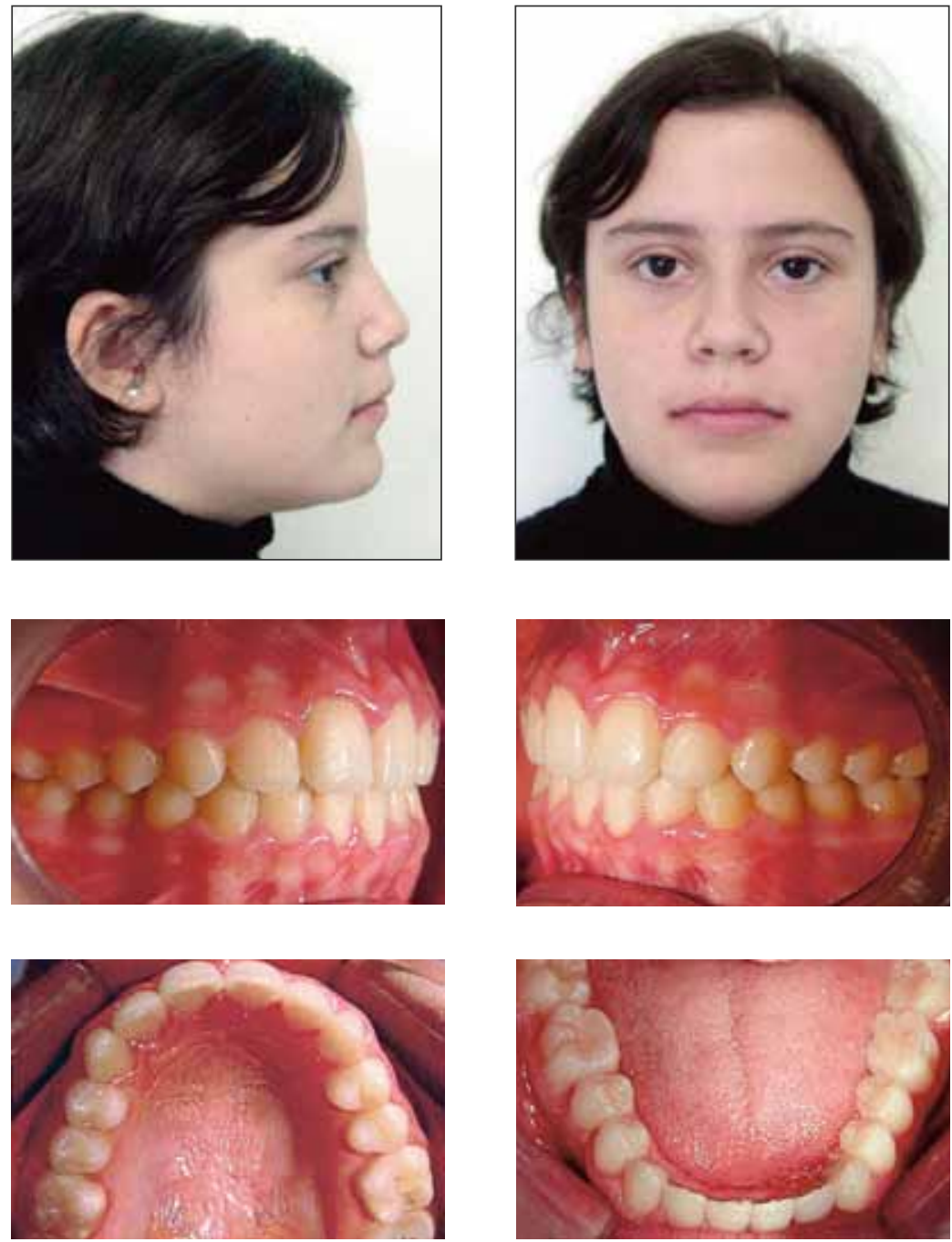

FIGURA 2 - Caso clínico 1: fotografias faciais e intrabucais finais.
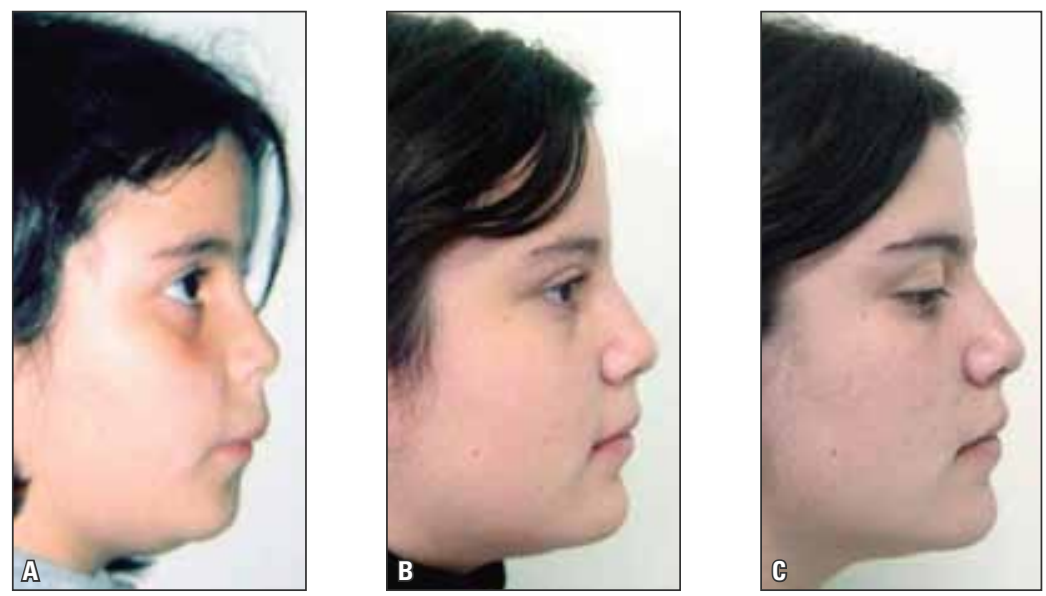

FIGURA 3 - Perfil pré (A), pós-tratamento (B) e três anos após a finalização do caso (C). 

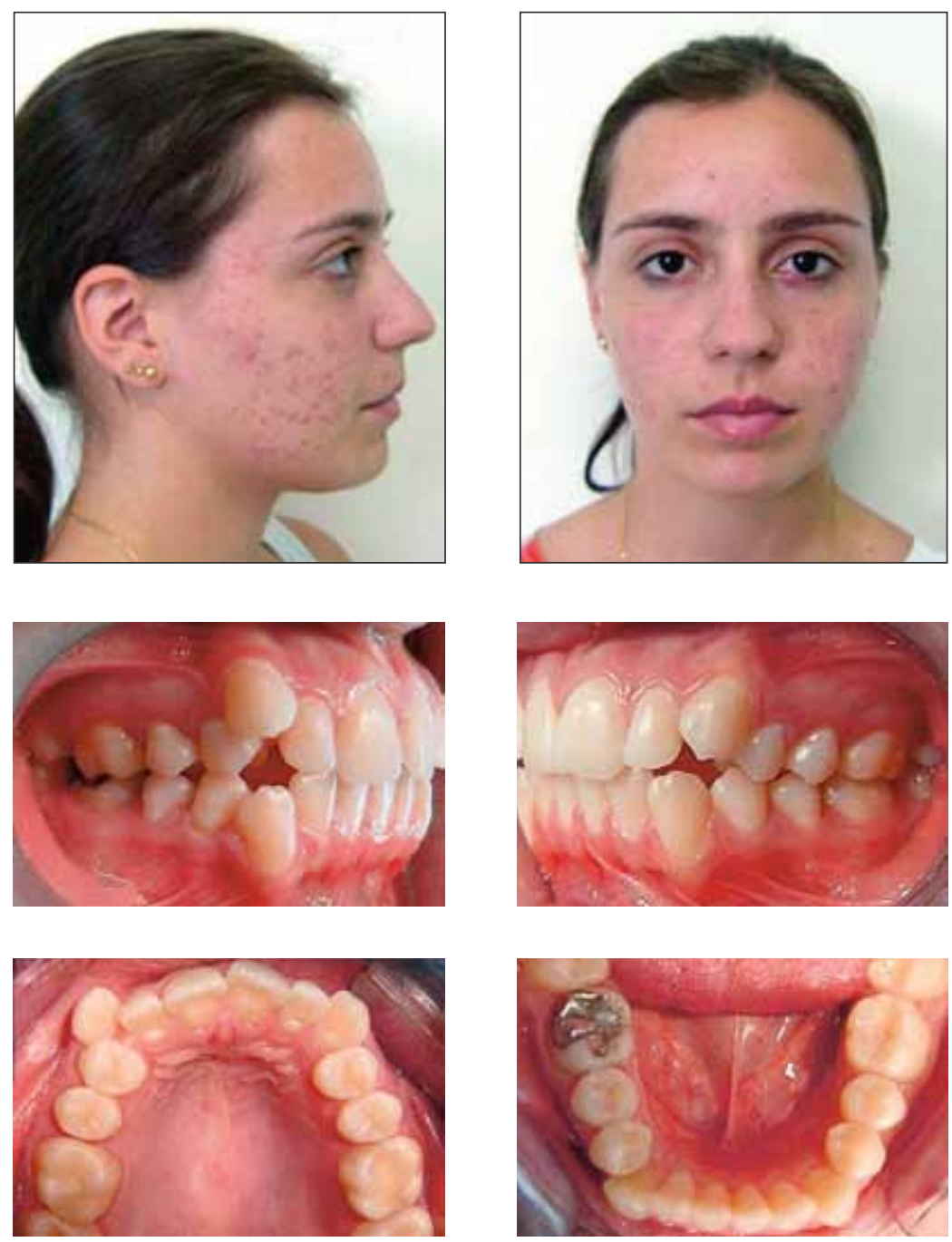

FIGURA 4 - Caso clínico 2: fotografias faciais e intrabucais iniciais.

\section{DISCREPÂNCIA CEFALOMÉTRICA E PERFIL FACIAL}

Em situações de acentuada inclinação vestibular dos incisivos, evidenciando-se grande discrepância cefalométrica (DC) e expressiva convexidade facial, muitas vezes são necessárias extrações para reposicioná-los, refletindo positivamente no perfil do paciente.

A tendência atual do diagnóstico ortodôntico é de valorizar mais as características faciais e se prender menos aos valores cefalométricos. Assim, algumas vezes, finaliza-se um caso com incisivos projetados em função de não alterar um perfil satisfatório, podendo-se lançar mão de desgastes interproximais (stripping) para criar espaços que possibilitem uma pequena verticalização desses dentes.

Nem sempre acontecem as alterações de perfil esperadas durante o tratamento ortodôntico. Boley et al. ${ }^{3}$ realizaram um estudo em 50 pacientes submetidos a tratamento ortodôntico com e sem extrações dentárias. Fotografias extrabucais dos pacientes antes e após o tratamento 

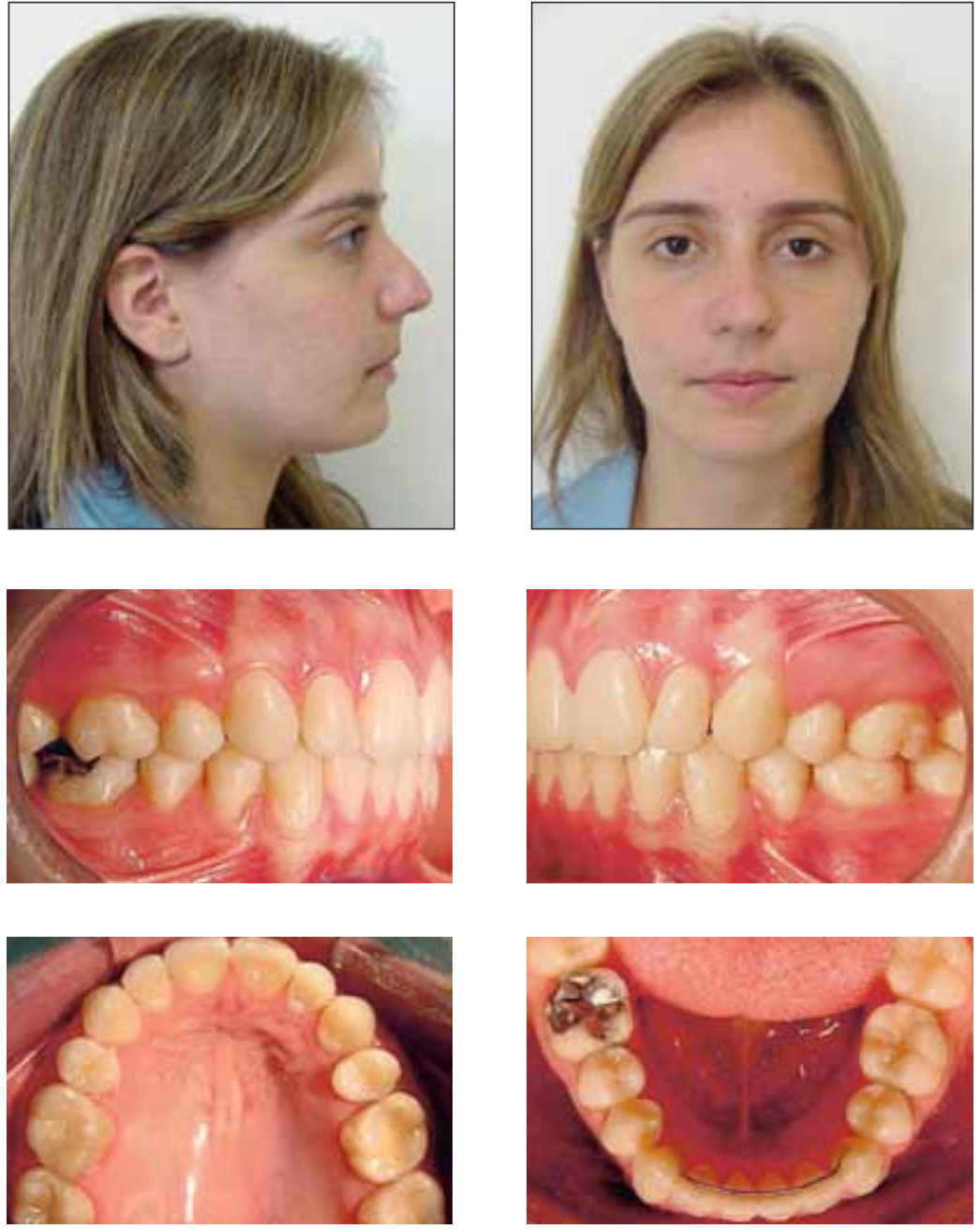

FIGURA 5 - Caso clínico 2: fotografias faciais e intrabucais finais.

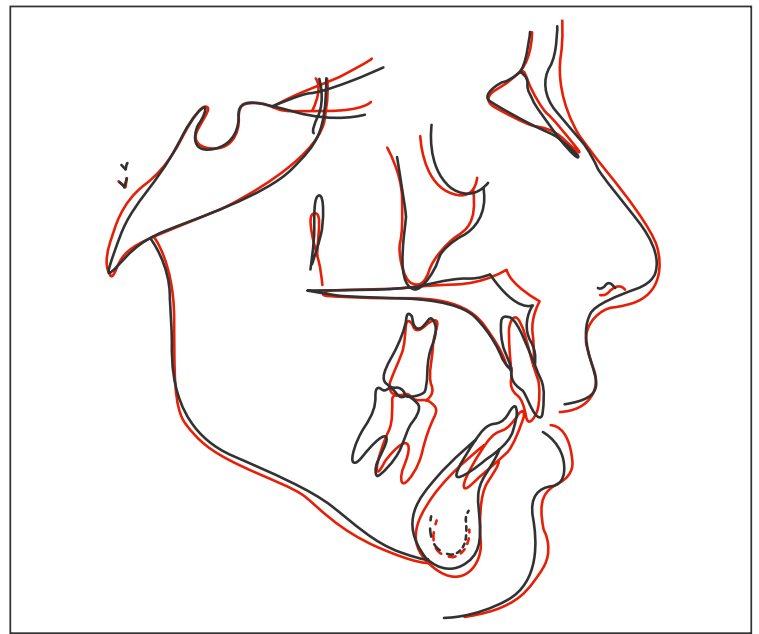

FIGURA 6 - Sobreposição total. foram enviadas a ortodontistas e clínicos norteamericanos para que respondessem que tipo de tratamento havia sido realizado. Num segundo momento, as mudanças no perfil dos pacientes foram avaliadas através de grandezas cefalométricas. Não foram encontradas diferenças estatisticamente significativas nas duas avaliações, concluindo-se que as mudanças no perfil não foram tão evidentes para cada tipo de tratamento.

Os pacientes podem apresentar perfis côncavos ou convexos em diferentes graus (acentuado, moderado ou leve) ou retos. De acordo com o tipo de perfil, pode-se decidir sobre a necessidade de extrações dentárias em um tratamento 
ortodôntico, haja vista que o perfil responderá às mudanças promovidas nos dentes. De acordo com Ramos et al. ${ }^{17}$, para cada $1 \mathrm{~mm}$ de retração do incisivo superior, o lábio superior se retrai em $0,75 \mathrm{~mm}$. Outros autores encontraram valores menores para essa relação $(1 / 0,64$ - Talass et al. ${ }^{20} ; 1 / 0,5$ - Massahud e Totti ${ }^{14}$ ). Quanto ao lábio inferior, para cada $1 \mathrm{~mm}$ de retração do incisivo inferior, o lábio se retrai em média $0,6 \mathrm{~mm}^{12}$ ou $0,78 \mathrm{~mm}^{14}$. Desse modo, o fechamento de espaços por retração dos dentes anteriores tenderá a tornar o perfil mais côncavo.

Há situações onde o perfil facial é côncavo mas o planejamento ortodôntico indica extrações para resolver problemas de apinhamento e/ou assimetrias dentárias anteroposteriores.

Atenção deve ser dada ao fato da estética facial estar sendo cada dia mais valorizada pelos pacientes e ao fato do perfil facial tornar-se mais côncavo à medida que a idade aumenta. Assim, deve-se preferir finalizar os casos com perfis levemente protrusos para que, no futuro, eles não se tornem côncavos. Em pacientes adultos, devese evitar a recolocação excessiva de dentes anteriores para lingual, o que poderá acarretar em evidenciação das rugas de expressão e imediato aspecto de envelhecimento facial.

As figuras 7 e 8 (caso clínico 3) mostram uma paciente com 11 anos de idade, perfil convexo, Classe II esquelética $\left(\mathrm{ANB}=6^{\circ}\right)$, Classe I dentária, $\mathrm{DM}$ inferior nula, sobressaliência de $2 \mathrm{~mm}$, mordida aberta de $3 \mathrm{~mm}$, incisivo superior bem posicionado (1.SN $\left.=103^{\circ}\right)$ e inferior projetado $\left(\right.$ IMPA $\left.=110^{\circ}\right)$. Como agravantes, a paciente apresentava respiração bucal e dificuldade em selar os lábios. Pode-se notar, também, o terço inferior da face aumentado e a falta de espaço para erupção dos caninos superiores.

Baseado nessas avaliações, optou-se pelo tratamento ortodôntico associado a extrações dos dentes 14 e 24 , com o objetivo de alinhar e nivelar os caninos superiores, e dos dentes 35 e 45 , para pequena reposição dos incisivos inferiores e movimento mesial dos dentes 36 e 46. Foi utilizada, também, mentoneira vertical durante o período noturno para controle vertical, evitando-se extrusões.

Ao final do tratamento (Fig. 9, 10), houve correção das relações dentárias e melhora no perfil facial, o qual não foi totalmente reposicionado, mostrando-se discretamente protruso, com a finalidade de evitar o envelhecimento precoce da paciente.

\section{IDADE ESQUELÉTICA (CRESCIMENTO) E RELAÇÕES ANTEROPOSTERIORES}

Nas más oclusões com discrepância esquelética, verificar se o paciente ainda apresenta crescimento facial expressivo é de fundamental importância no diagnóstico e prognóstico do caso. O surto máximo de crescimento puberal ocorre, aproximadamente, por volta dos 11 a 12 anos nas meninas e 13 a 14 anos nos meninos, excetuandose as variações individuais ${ }^{16}$. O método mais utilizado para avaliação da idade esquelética é a radiografia de mão e punho, analisando-se o tamanho das epífises em relação às diáfises ${ }^{9}$. Caso o paciente se encontre nesse período do desenvolvimento, é possível corrigir uma displasia esquelética com uso de aparelhos com efeitos ortopédicos.

Caso a má oclusão possa ser corrigida com resposta do crescimento (redirecionamento do crescimento), o clínico tem a possibilidade de tratar o caso sem extrações dentárias.

As figuras 11 e 12 (caso clínico 4) demonstram um caso clínico com essas características. Utilizando-se aparelho extrabucal associado a aparelho ortodôntico fixo, obteve-se correção dentária e esquelética. Inicialmente, o paciente com 11 anos de idade apresentava perfil convexo; Classe II esquelética $\left(\mathrm{ANB}=8^{\circ}\right)$; Classe II, divisão 1; DM inferior de $2 \mathrm{~mm}$; sobressaliência de $8 \mathrm{~mm}$; sobremordida de $5 \%$; incisivos superiores bem posicionados $\left(1 . \mathrm{SN}=101^{\circ}\right)$ e inferiores projetados $\left(\mathrm{IMPA}=99^{\circ}\right)$; e terço inferior da face aumentado. Como agravante, o paciente apresentava hábito de sucção de dedo, respiração bucal e possuía crescimento com resultante predominantemente vertical $\left(\mathrm{Sn} . \mathrm{GoGn}=40^{\circ}\right)$. 

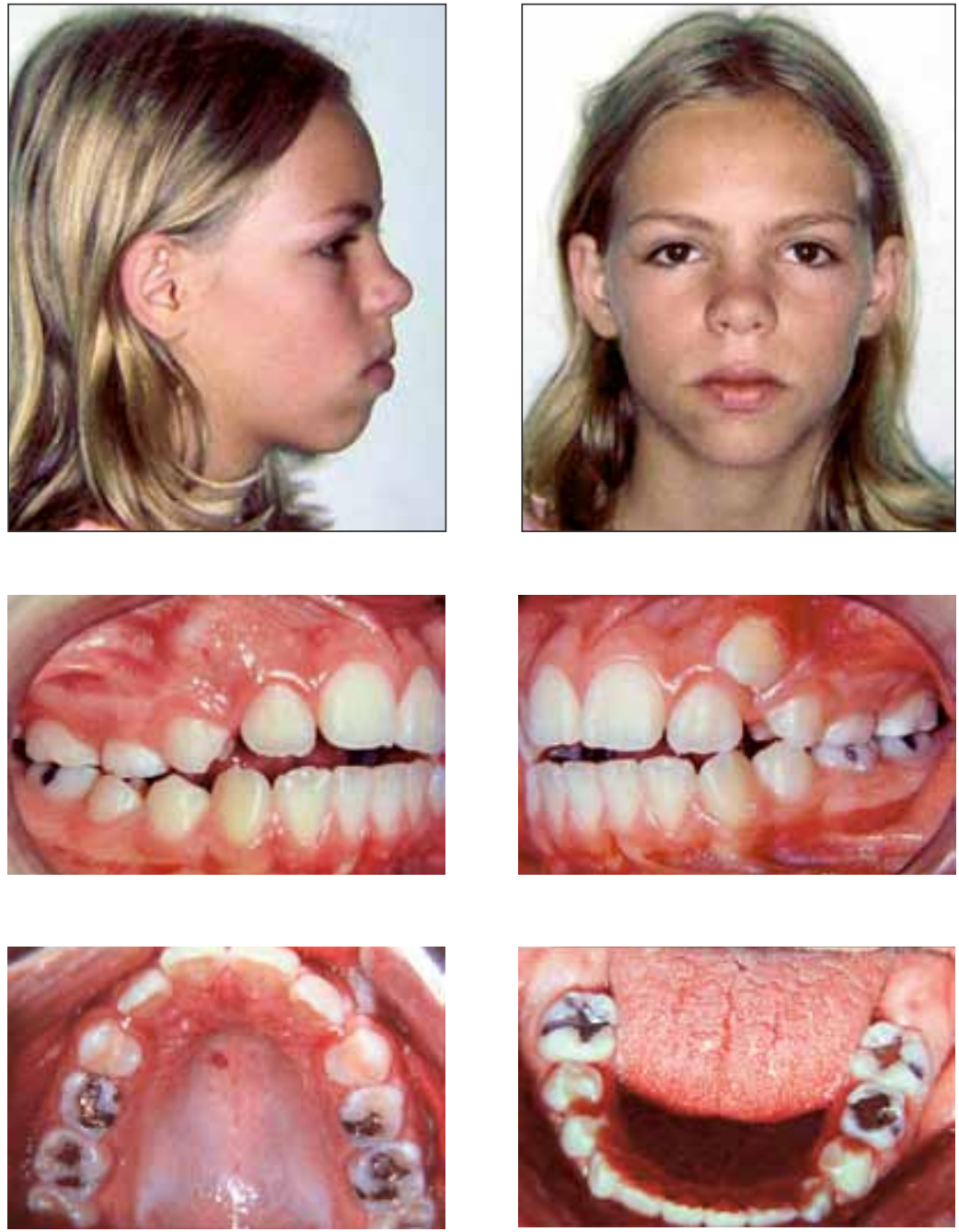

FIGURA 7 - Caso clínico 3: fotografias faciais e intrabucais iniciais.

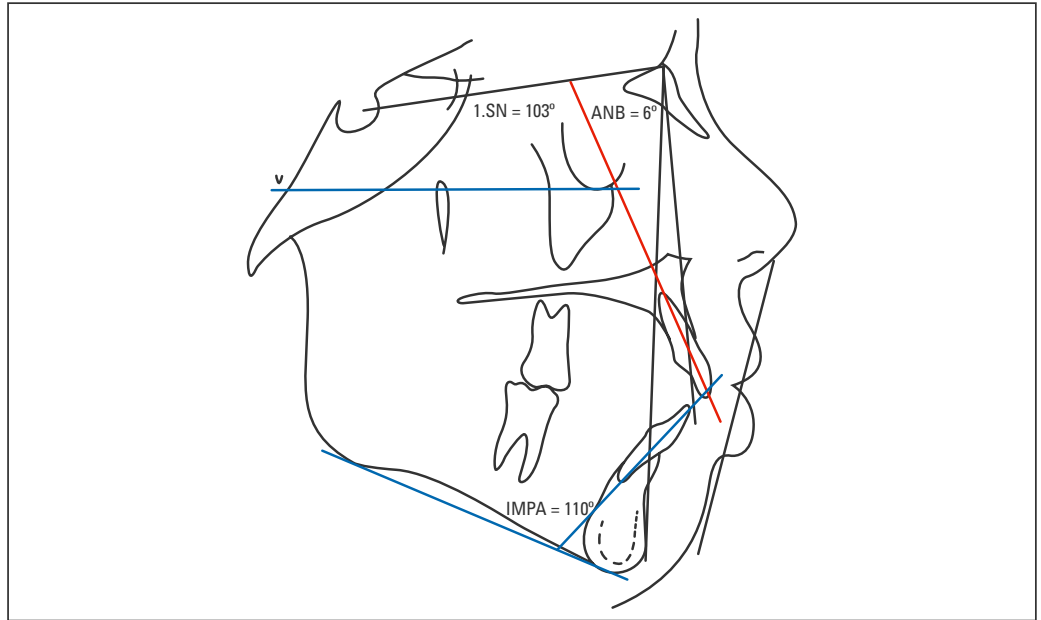

FIGURA 8 - Traçado cefalométrico inicial. 

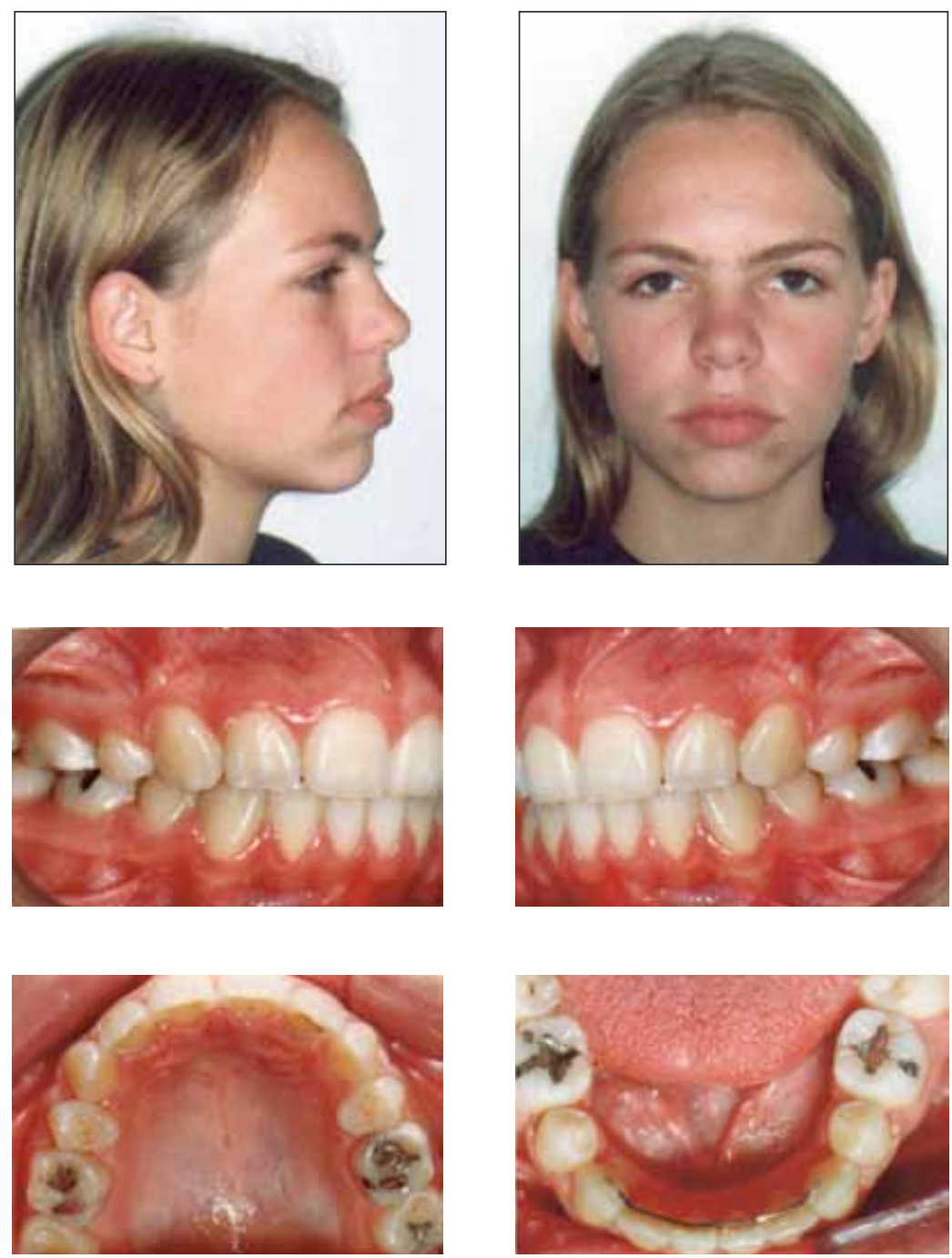

FIGURA 9 - Caso clínico 3: fotografias faciais e intrabucais finais.

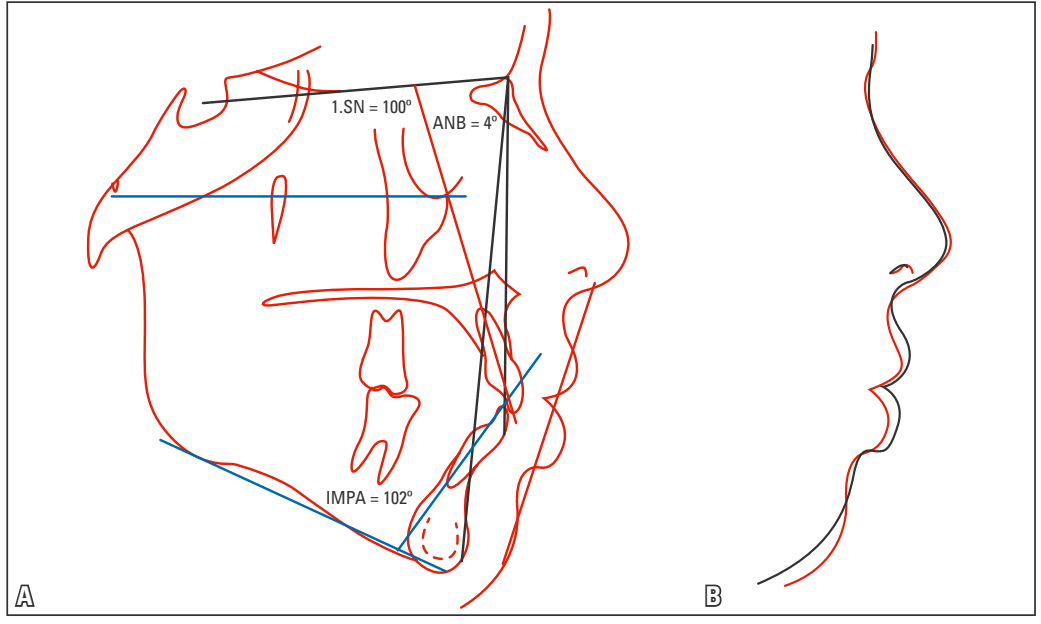

FIGURA 10 - A) Traçado cefalométrico final e B) comparação dos perfis inicial e final. 

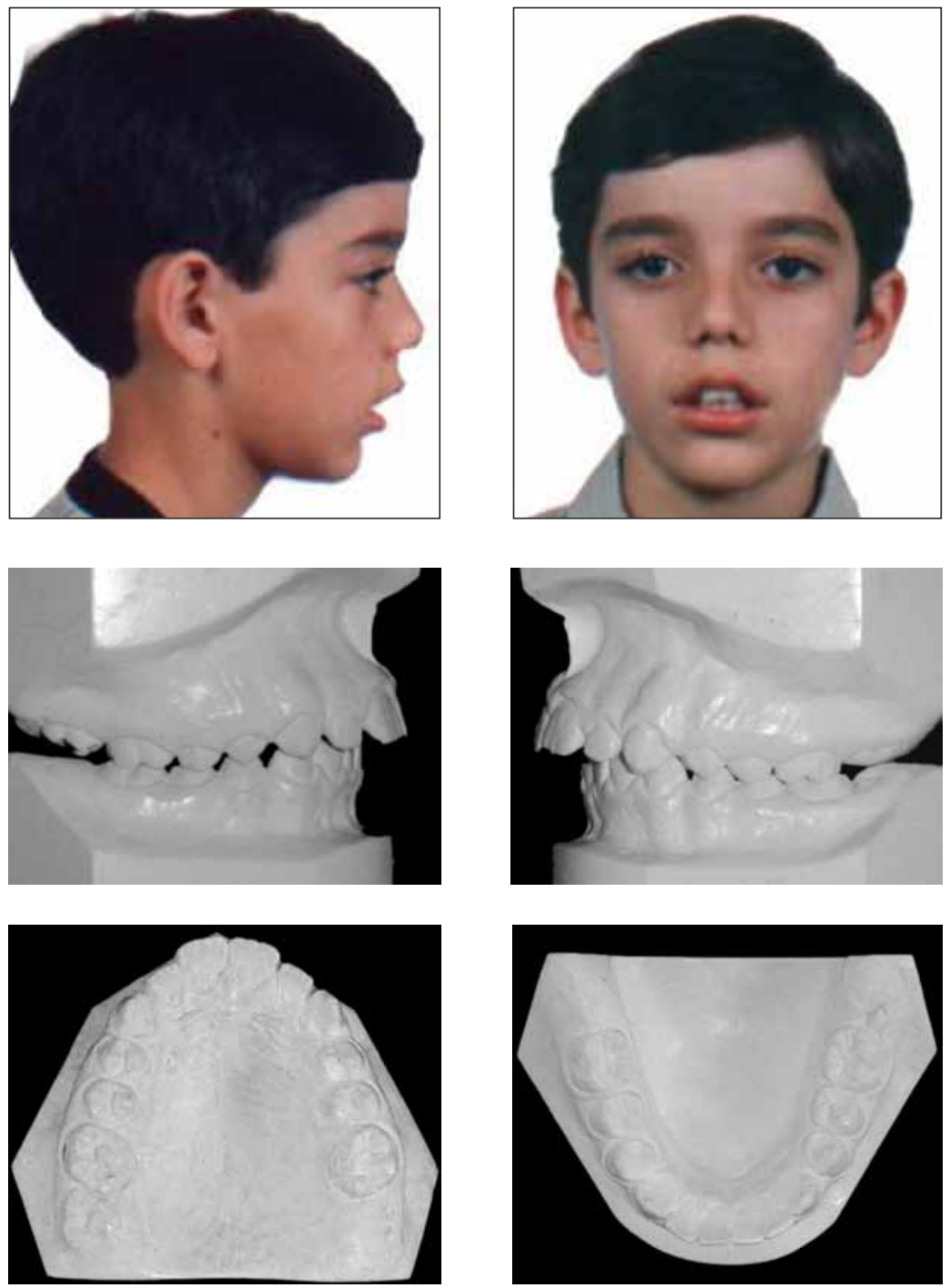

FIGURA 11 - Caso clínico 4: fotografias faciais e dos modelos iniciais.

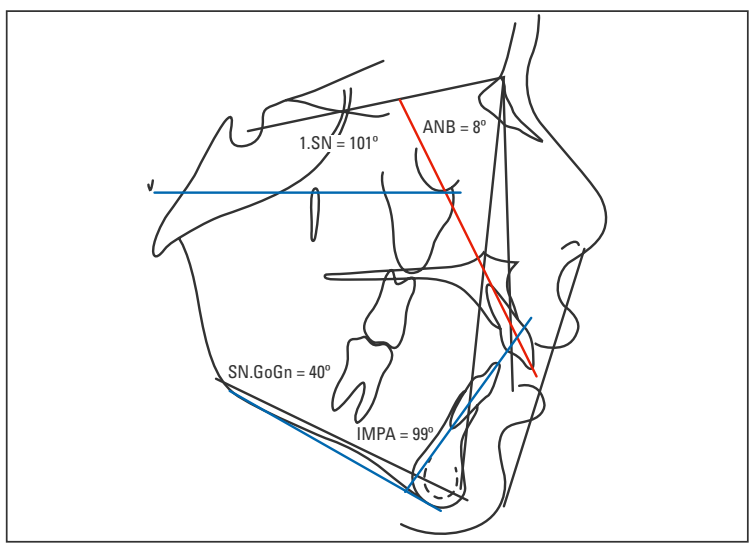

FIGURA 12 - Traçado cefalométrico inicial.
Nesse caso, optou-se por utilizar o aparelho extrabucal de tração combinada com maior componente vertical, para corrigir a Classe II por diferença de deslocamento da mandíbula para anterior (em decorrência do crescimento), associado ao uso de elásticos de Classe III, para reposicionamento dos incisivos inferiores.

Ao final do tratamento, obteve-se correção das relações esqueléticas ( $\mathrm{ANB}=3^{\circ}$ ) e dentárias às custas da restrição do crescimento anteroposterior e vertical da maxila, além de movimento distal dos dentes superiores e boa resposta do crescimento mandibular para anterior. 

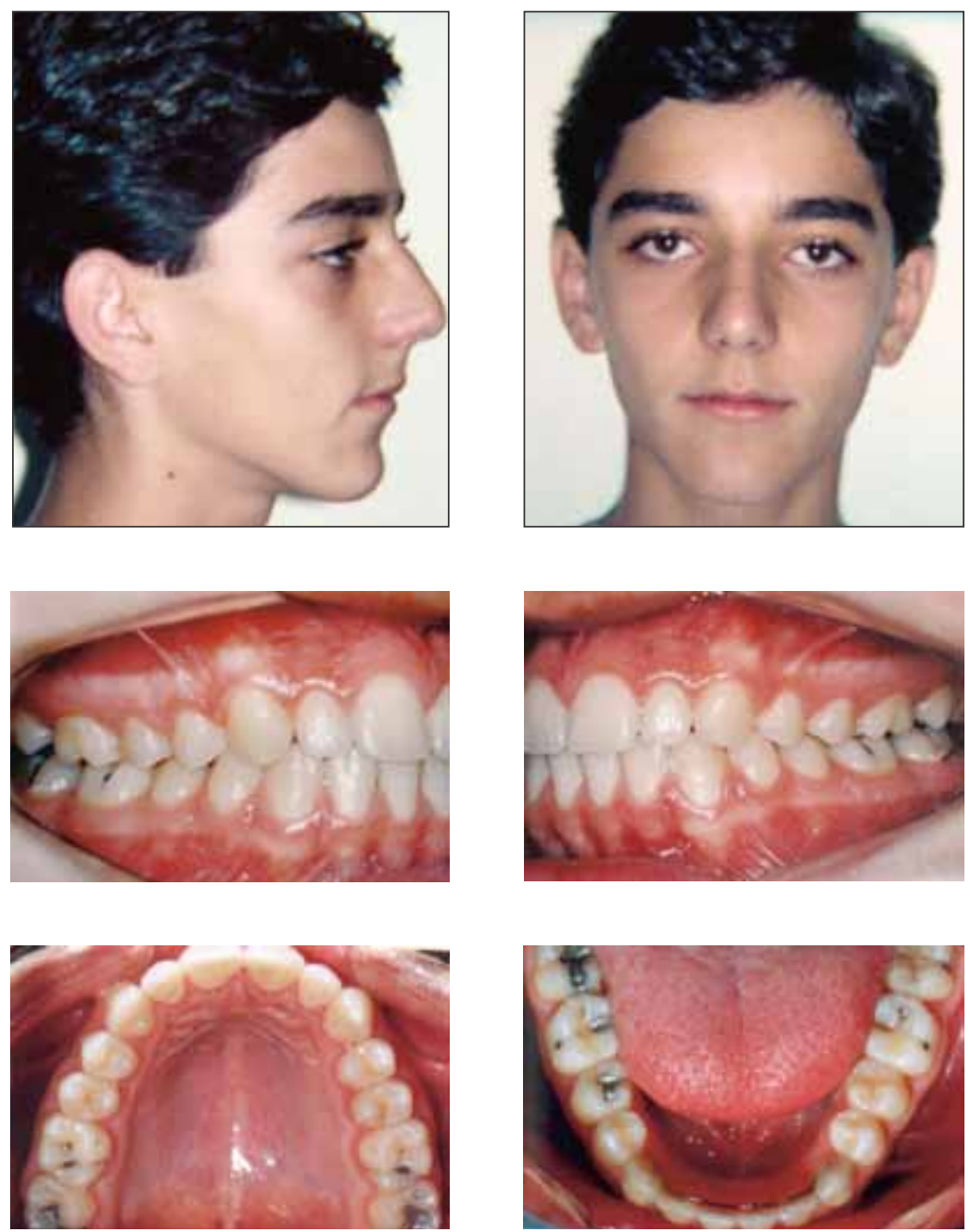

FIGURA 13 - Caso clínico 4: fotografias faciais e intrabucais finais.

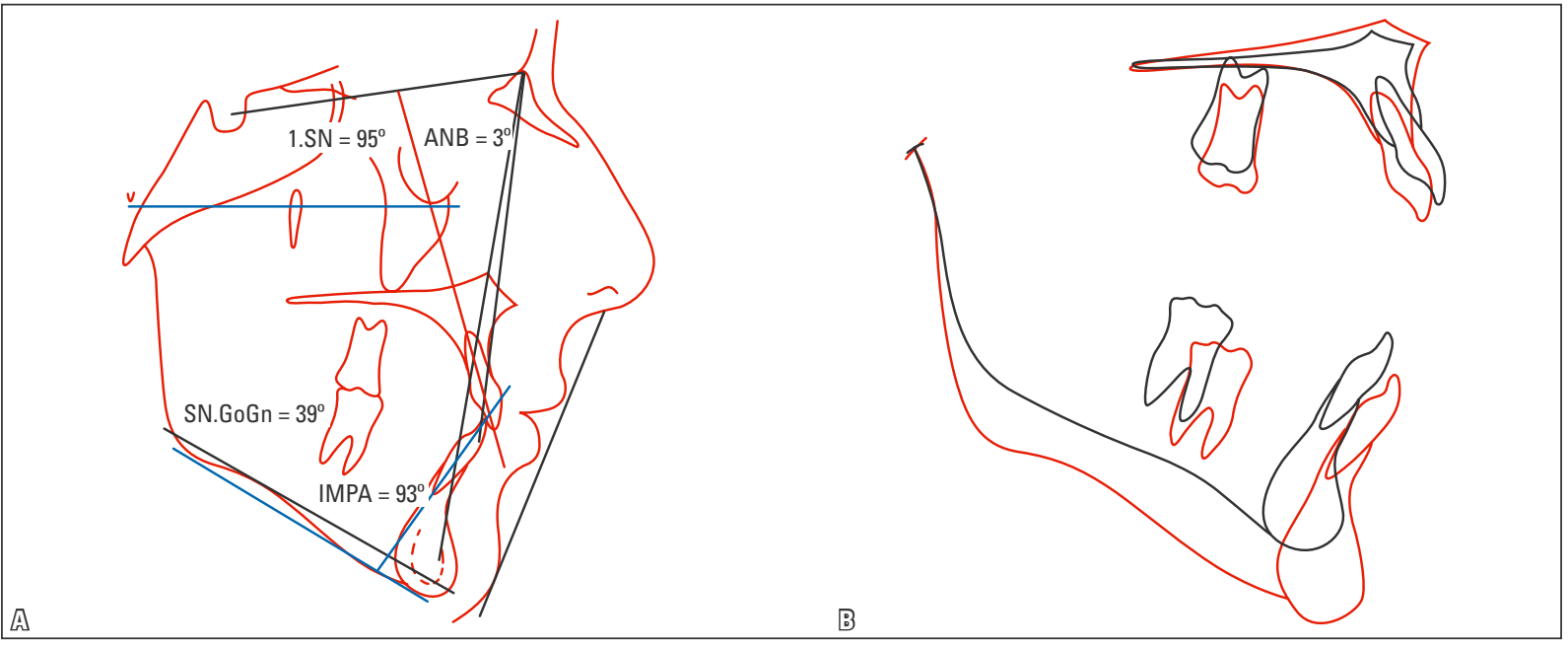

FIGURA 14 - A) Traçado cefalométrico final e B) sobreposições parciais da maxila e mandíbula. 
Com o melhor posicionamento dentário e esquelético, o paciente obteve selamento labial passivo (Fig. 13, 14).

No paciente adulto, que obviamente não apresenta mais crescimento suficiente para a correção de um problema esquelético ${ }^{8}$, uma alternativa viável é a extração de dentes para solucionar os distúrbios oclusais, mascarando o problema esquelético, ou então a realização de cirurgia ortognática.

Os retratamentos ortodônticos muitas vezes enquadram-se nessa situação, pois a correção do problema esquelético, que poderia ter sido realizada na fase de surto de crescimento, algumas vezes não ocorreu completamente e, no retratamento, as extrações acabam sendo uma possível solução para resolver discrepâncias anteroposteriores. Os retratamentos tornam-se mais complexos porque, normalmente, apresentam limitações: a melhor opção já foi desperdiçada, dentes já foram extraídos, reabsorções radiculares podem estar presentes, o paciente apresenta desgaste emocional e não encontra-se mais em fase de crescimento.

Quando da execução de um tratamento prévio em que o crescimento não foi aproveitado para correção da má oclusão e foram realizadas extrações dentárias, uma conduta a ser discutida é o tratamento combinando Ortodontia com Cirurgia Ortognática. O caso 5 exemplifica bem essa situação.

As figuras 15 e 16 são de uma paciente com 26 anos de idade, apresentando perfil convexo; Classe II esquelética; Classe II, divisão 2 de Angle; DM inferior nula; sobressaliência de $4 \mathrm{~mm}$; sobremordida de 40\%; exposição excessiva de incisivo superior; terço inferior da face aumentado; e ausência dos dentes 35 e 45 (ausentes congenitamente), 14 e 24 (extraídos em tratamento prévio). A paciente tinha como queixa principal a estética dentária e facial. As possíveis soluções para resolução desse caso seriam a utilização de recursos para distalização de dentes superiores - obtendo-se apenas correção dentária e, provavelmente, tornando a estética facial pior - ou a eliminação da compensação das inclinações dentárias para posterior realização de cirurgia ortognática com impacção da maxila e avanço mandibular.

Com base na queixa da paciente, optou-se pelo tratamento ortocirúrgico com alinhamento e nivelamento, eliminando-se as compensações dentárias; extrações dos dentes 18, 38 e 48; impacção de maxila; avanço de mandíbula e mentoplastia.

Os resultados obtidos foram a harmonização das relações oclusais, com bom posicionamento dos dentes em suas bases ósseas, e a correção das desarmonias esqueléticas (Fig. 17, 18).

\section{ASSIMETRIA DENTÁRIA}

A avaliação das estéticas dentária e facial é item importante no processo de diagnóstico e planejamento do tratamento ortodôntico. Um dos maiores desafios nesse binômio é o correto posicionamento das linhas medianas dentárias superior e inferior entre si e em relação à face ${ }^{4}$.

Segundo Strang ${ }^{19}$, o posicionamento harmonioso das linhas medianas dentárias entre si e dessas com a facial é característica da oclusão normal, sendo que qualquer variação nessa combinação é indicativa de relacionamento inadequado entre os dentes ou arcadas dentárias. Dessa maneira, requer atenção em seu diagnóstico, pois a avaliação adequada da causa dos desvios permite ao profissional usar mecânicas diferenciadas e extrações assimétricas ${ }^{21}$.

Segundo Lewis ${ }^{13}$, várias maneiras são propostas para se fazer o diagnóstico de desvios das linhas medianas. Chiche e Pinault ${ }^{6}$ relataram que a avaliação deve ser baseada em três fatores: centro do lábio superior, posição da papila e inclinação dos incisivos centrais. $O$ diagnóstico pode ser realizado também por meio de modelos de gesso bem recortados ${ }^{5}$, marcando-se dois ou três pontos na região mais posterior da rafe palatina mediana e posicionando a placa reticulada superpondo esses pontos ${ }^{16}$. 

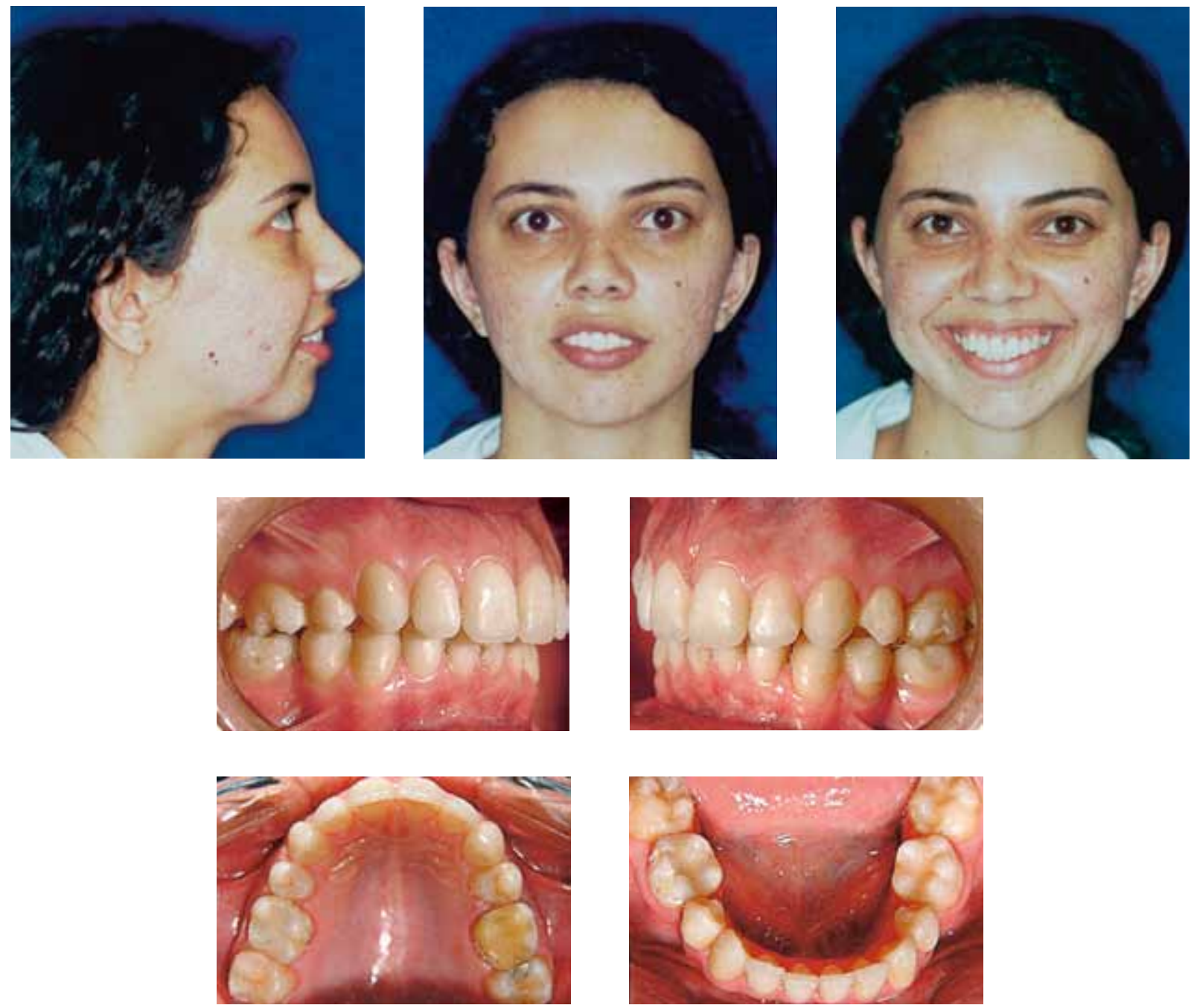

FIGURA 15 - Caso clínico 5: fotografias faciais e intrabucais iniciais.

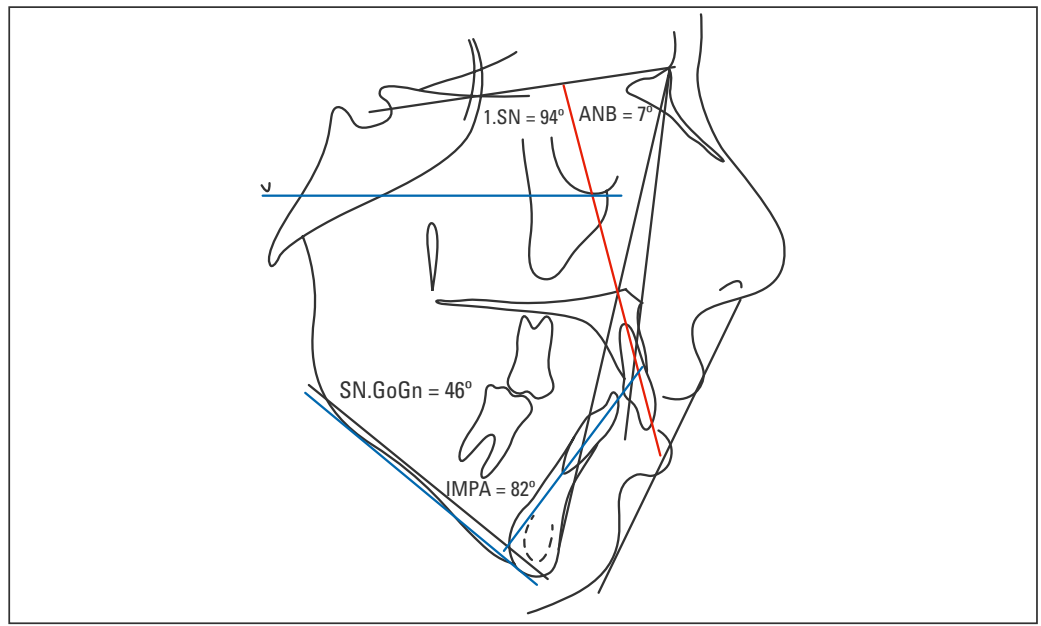

FIGURA 16 - Traçado cefalométrico inicial. 

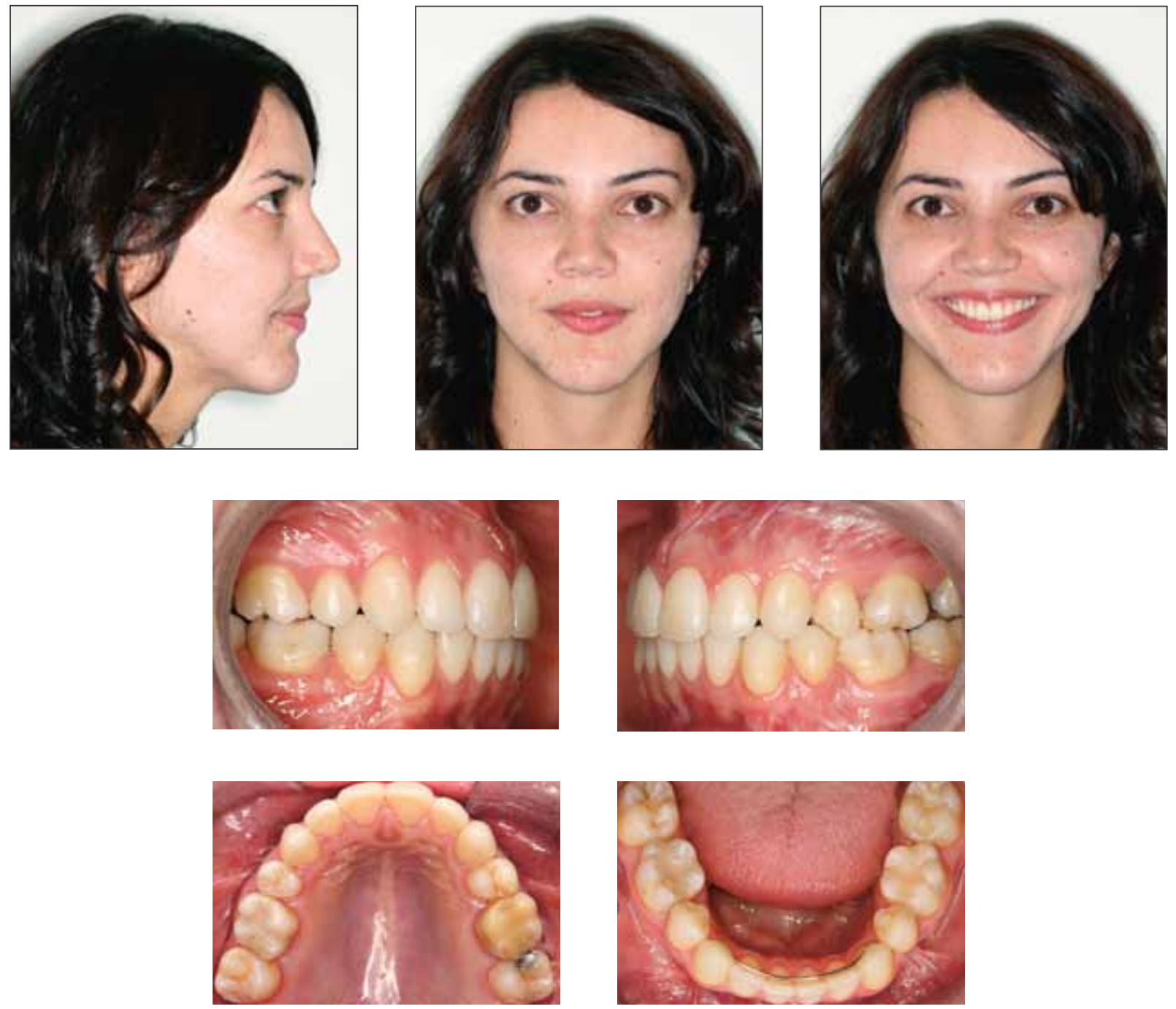

FIGURA 17 - Caso clínico 5: fotografias faciais e intrabucais finais.

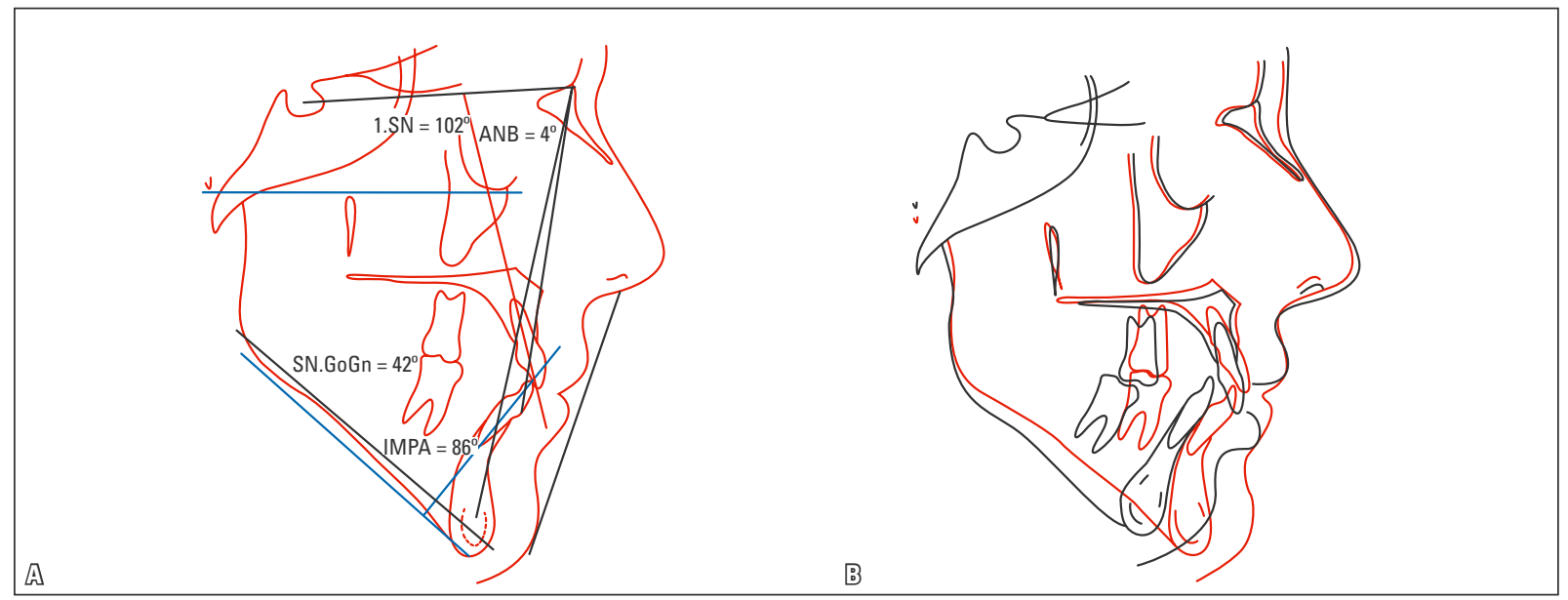

FIGURA 18 - A) Traçado cefalométrico final e B) sobreposição total. 
Nas más oclusões de Classe II, subdivisão, que apresentam simetria de bases ósseas, porém assimetria dentária, o ortodontista deve determinar qual segmento dentário é responsável pelo desvio e avaliar a linha mediana dentária em relação à face para elaboração do plano de tratamento compatível com a situação apresentada ${ }^{25}$.

Em pacientes que apresentem acentuado desvio da linha média dentária em relação à facial (principalmente na arcada inferior), tornase necessária a realização de exodontias dentárias. Pequenas assimetrias podem ser corrigidas com elásticos intermaxilares ou mini-implantes (em alguns casos, com mecânica unilateral), extrações assimétricas, desgastes interproximais e, em poucas situações, aceitar finalizar o tratamento ortodôntico com pequeno desvio da linha mediana. A ausência de coincidência entre as linhas médias dentária e facial é mais notada na arcada superior, sendo esteticamente desagradável. Esse desvio pode representar o motivo principal de muitos pacientes para a procura por tratamentos ortodônticos.

Para ilustrar essa situação, será apresentado o caso clínico 6, de uma paciente com 18 anos de idade que apresentava má oclusão de Classe II esquelética $\left(A N B=8^{\circ}\right)$, incisivos superiores e inferiores bem posicionados $\left(1 . S N=104^{\circ}\right.$ e IMPA $=92^{\circ}$ ), perfil facial reto (LS-S $=2 \mathrm{~mm}$ e LI-S = $1 \mathrm{~mm})$. No que concerne ao relacionamento dentário, o caso apresentava-se com grande assimetria inferior devido a um tratamento prévio com extração apenas do elemento 44, DM inferior de $-3 \mathrm{~mm}$, sobressaliência de $2 \mathrm{~mm}$ e sobremordida de 50\% (Fig. 19, 20).

Com base nos referidos dados de diagnóstico, optou-se pela extração do dente 34 para corrigir a assimetria inferior. No entanto, apenas a extração desse dente corrigiria a assimetria inferior, mas levaria a relação de caninos do lado esquerdo para Classe II. Para evitar tal efeito indesejado, foram necessárias extrações superiores dos segundos pré-molares (15 e 25).
A extração do dente 25 propiciou manutenção da relação de chave de oclusão nos caninos do lado esquerdo, e a do elemento 15 manteve a simetria na arcada superior.

Inicialmente, uma dúvida pode surgir ao avaliar esse caso clínico. Como fazer para que as extrações dentárias não piorem o perfil da paciente, que estava adequado no início do tratamento? Para se evitar a piora no perfil, foram utilizados recursos mecânicos de torque resistente, vestibular de coroa nos incisivos inferiores e ômegas justos aos tubos dos segundos molares, para que não ocorresse reposição lingual do incisivo inferior, além de apoio em mini-implante para perder ancoragem na hemiarcada inferior direita. Desse modo obteve-se, ao final do tratamento, correção da má oclusão de Classe II dentária sem comprometimento do perfil facial (Fig. 21, 22).

Vale ressaltar que, após finalização do tratamento, a paciente submeteu-se a uma cirurgia de rinoplastia, para melhor compor a estética do perfil.

\section{PADRÃO FACIAL}

Pacientes com diferentes padrões faciais requerem mecânicas diferenciadas e as respostas ao tratamento ortodôntico não são semelhantes. Pacientes dolicofaciais são aqueles que apresentam a altura da face maior do que a largura, evidenciando uma face longa, estreita e protrusiva. Além disso, possuem musculatura facial hipotônica no sentido vertical, podendo apresentar mordida aberta anterior ${ }^{8}$. Nesses pacientes, normalmente ocorre maior perda de ancoragem, o que auxilia no fechamento de espaços, porém, necessita-se de maior controle para evitar a perda excessiva de ancoragem e a consequente falta de espaço para a devida correção planejada. Mecânicas extrusivas devem ser evitadas, bem como o movimento distal de dentes posteriores.

Os pacientes braquifaciais apresentam a largura da face maior do que a altura, evidenciando-se uma face larga, curta e globular ${ }^{8}$. Nesses pacientes, a perda de ancoragem, geralmente, é 

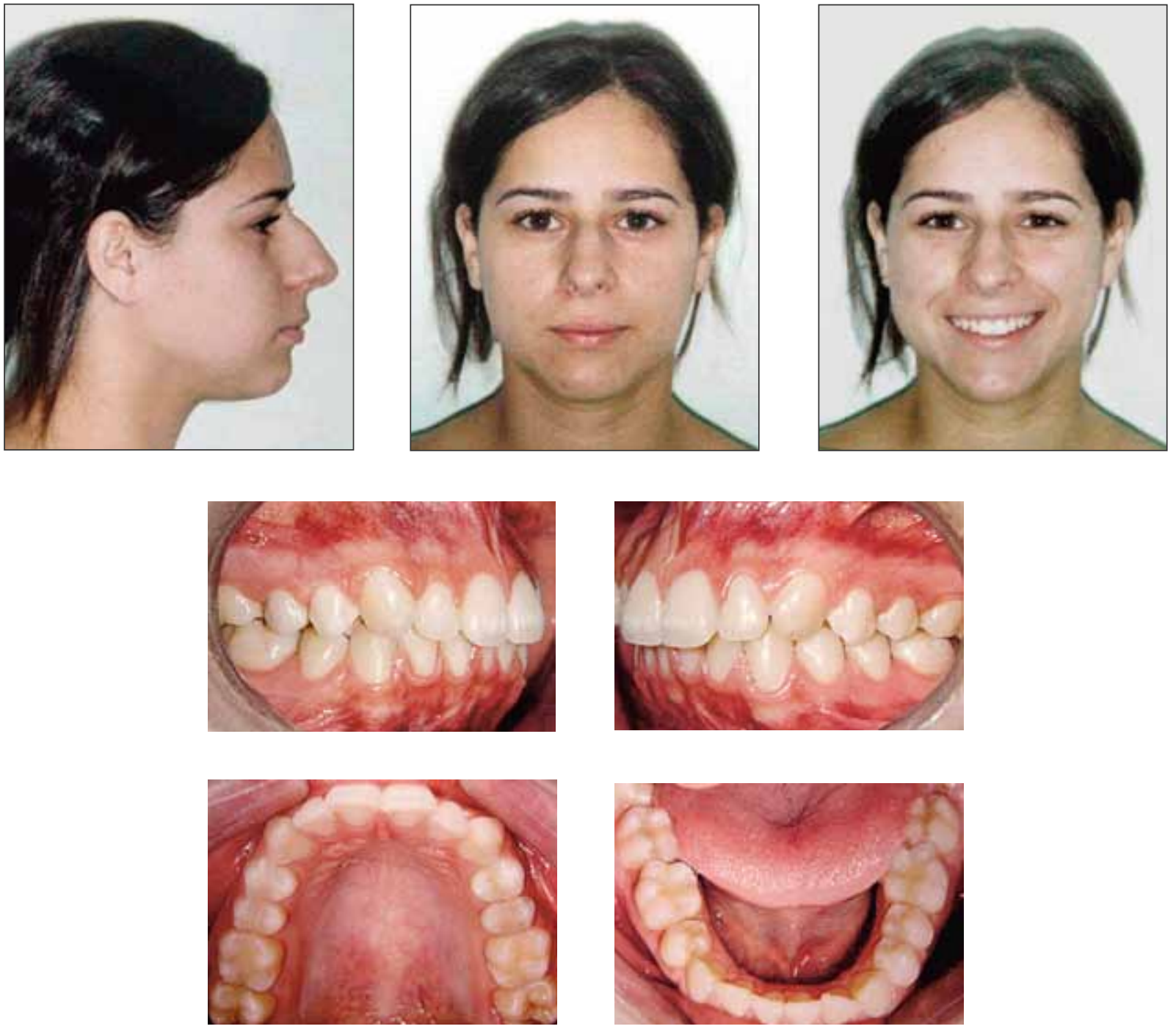

FIGURA 19 - Caso clínico 6: fotografias faciais e intrabucais iniciais.

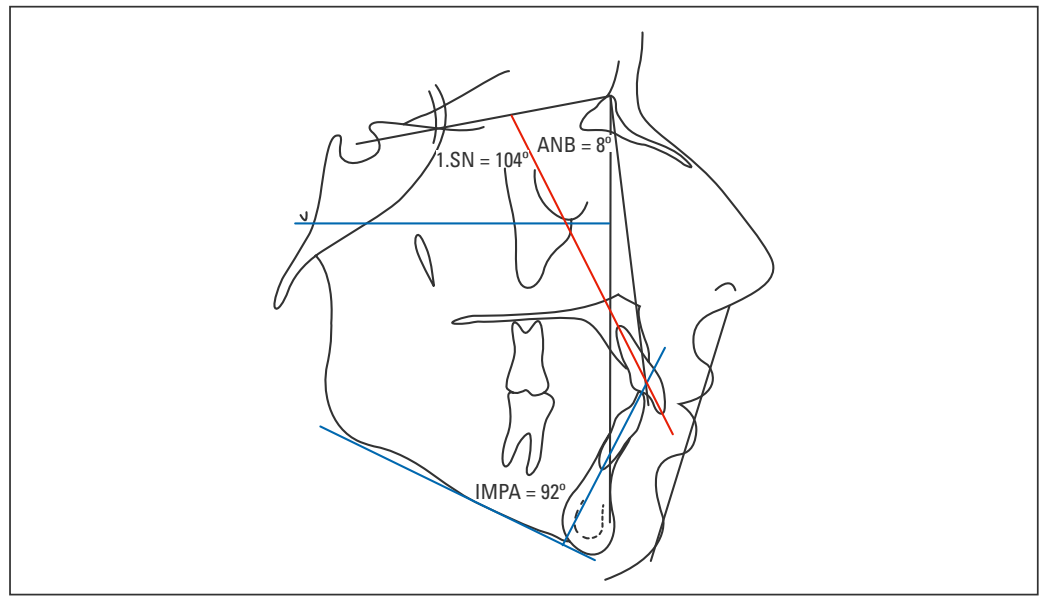

FIGURA 20 - Traçado cefalométrico inicial. 

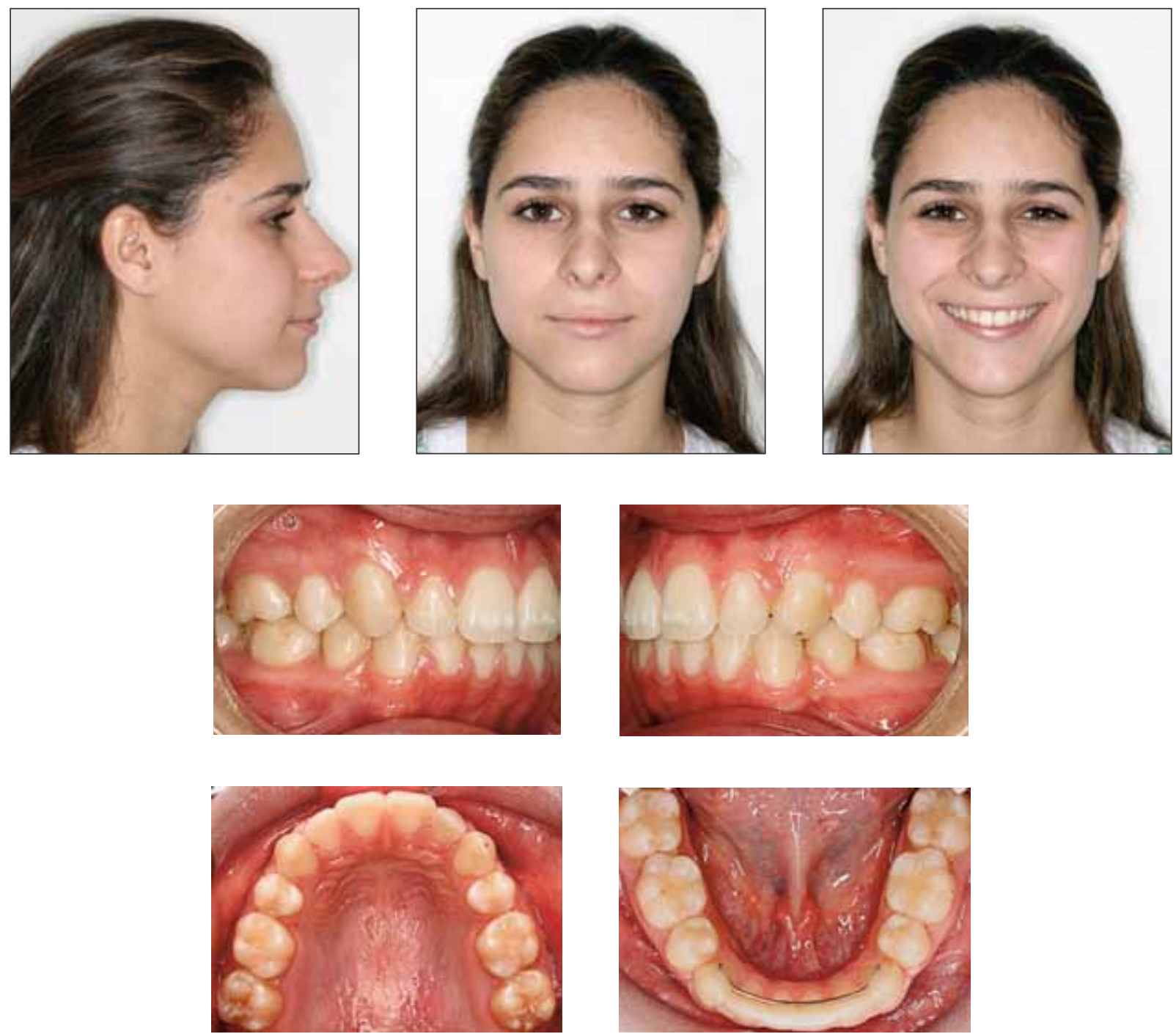

FIGURA 21 - Caso clínico 6: fotografias faciais e intrabucais finais.

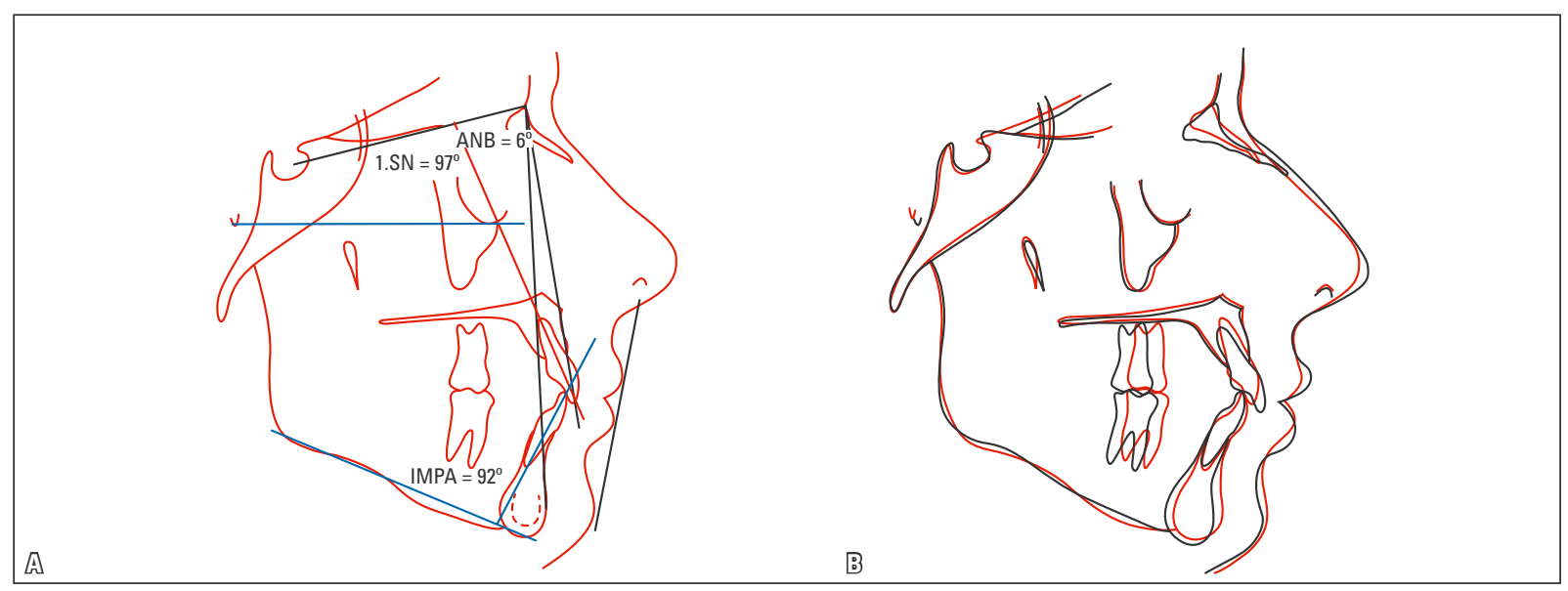

FIGURA 22 - A) Traçado cefalométrico final e B) sobreposição total. 
mais difícil de ocorrer devido às características de sua musculatura (músculos da mastigação hipertônicos), o que dificulta a movimentação dentária. Muitos pacientes braquicefálicos apresentam mordida profunda. Nesses casos, extrações dentárias tenderiam a piorar esse trespasse vertical, necessitando de um bom controle mecânico. Apesar de normalmente ocorrer maior perda de ancoragem no dolicocefálico e menor no braquicefálico, nem sempre isso acontece. Portanto, cuidado adicional deve ser tomado durante a fase de fechamento de espaços.

A literatura sugere a remoção de dentes permanentes posteriores e subsequente perda de ancoragem para correção da mordida aberta anterior pela rotação anti-horária da mandíbulala ${ }^{1,15}$. Por outro lado, há autores ${ }^{10}$ que questionam essa associação entre diminuição do crescimento vertical e extrações.

Entretanto, a experiência clínica evidencia que o movimento dos dentes posteriores para distal provoca tendência à abertura do plano mandibular, principalmente em pacientes que já passaram o surto de crescimento ou que tenham padrão de crescimento desfavorável (predominantemente vertical), o que remete à maior necessidade de extrações. Por outro lado, a realização de extrações associada ao controle vertical (uso de mentoneira vertical, AEB tração alta, mini-implantes, sem utilização de mecânicas extrusivas) pode resultar no fechamento do plano mandibular e/ou controle do crescimento vertical da face com diminuição do terço inferior e melhora do selamento labial (Fig. 7 a 10).

Para elucidar essa situação, apresentamos o caso clínico 7 (Fig. 23), onde foi realizado o tratamento ortodôntico em paciente com padrão facial vertical. No exame clínico, foi identificada mordida aberta anterior e posterior. O planejamento indicou extrações dos segundos molares superiores, aproveitamento dos elementos 18 e 28, além da colocação de mini-implantes ortodônticos para intruir os molares superiores, movimentá-los para distal e para manutenção da ancoragem durante a retração dentária. O apinhamento inferior foi resolvido com stripping, principalmente nos incisivos que apresentavam formato triangular, com presença de espaços negros, quando alinhados. Os resultados obtidos, nesse caso, foram a correção da relação dentária de Classe II com fechamento da mordida através de intrusão de molares superiores (Fig. 24). A sobreposição total evidencia a intrusão do molar superior, diminuição do plano mandibular pela rotação anti-horária da mandíbula e consequente fechamento da mordida aberta (Fig. 25).

\section{PATOLOGIAS}

Algumas patologias têm grande contribuição na definição do planejamento do tratamento ortodôntico. Os pacientes podem apresentar dentes que interromperam sua formação, agenesias, ectopias, anomalias de forma ou, até mesmo, processos cariosos e lesões endodônticas que indiquem a extração do dente. No diagnóstico, essas patologias devem ser consideradas, podendo alterar, em determinadas situações, o planejamento do dente a ser extraído.

Em pacientes com indicação de extrações de pré-molares devido à acentuada discrepância negativa de modelo, mas que apresentam os primeiros molares permanentes acometidos por cárie extensa, esses últimos dentes tornam-se alternativa viável de extração ao invés dos pré-molares ${ }^{22}$. Em más oclusões assimétricas, onde apenas um dente deve ser extraído e o paciente apresenta um elemento anômalo, esse deve ser o escolhido. Muitas outras situações patológicas - como cistos, anomalias radiculares e problemas periodontais - indicam a extração de elementos dentários. Dessa forma, as patologias contribuem bastante para tratamentos ortodônticos com extração.

O caso clínico 8, de uma paciente com 10 anos de idade, ilustra a importância das patologias na decisão de qual dente extrair. A mesma encontrava-se na fase de dentição mista, apresentava má 

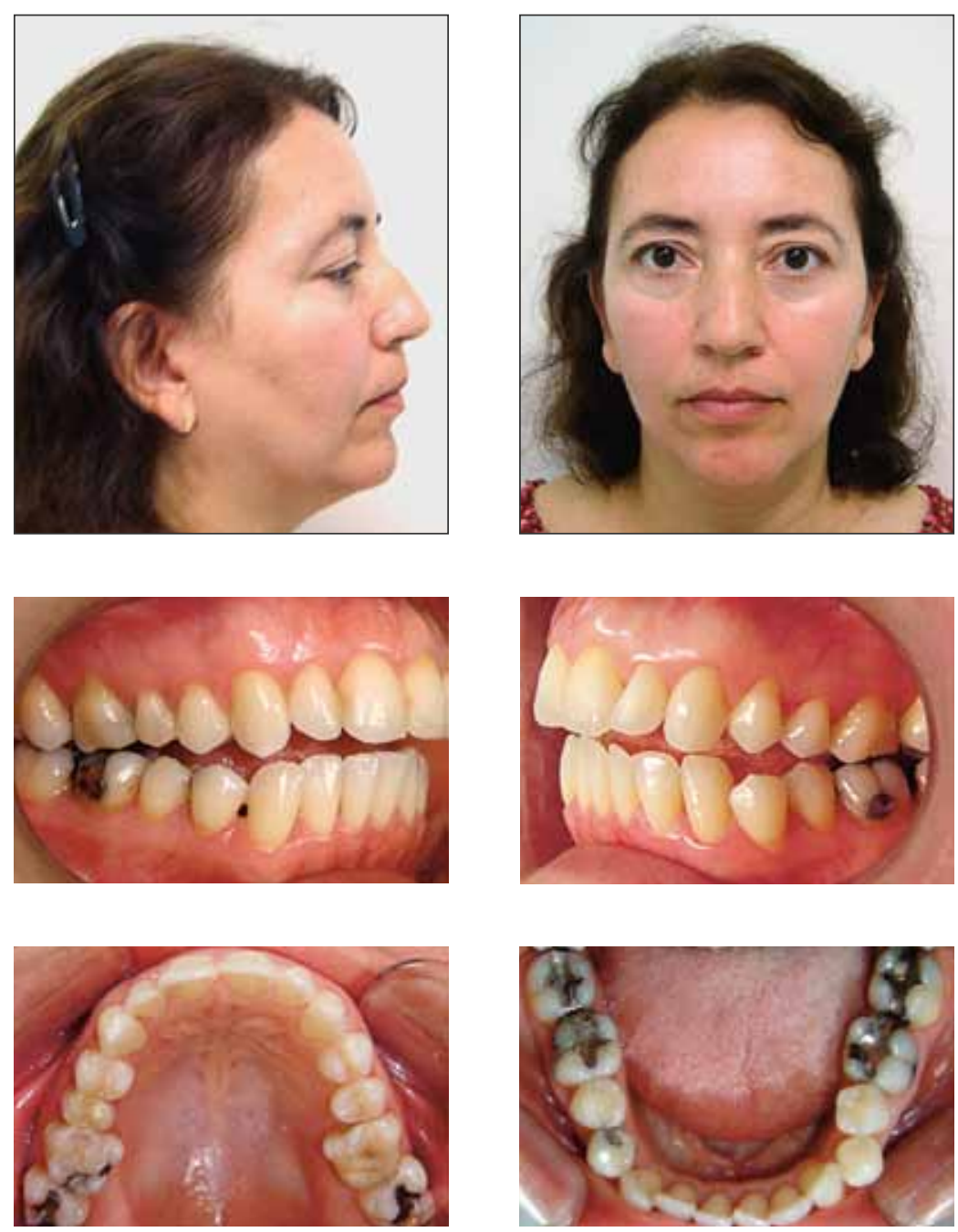

FIGURA 23 - Caso clínico 7: fotografias faciais e intrabucais iniciais.

oclusão de Classe I de Angle, mordida aberta anterior de $3 \mathrm{~mm}$, respiração bucal, linha média superior desviada em virtude da falta do elemento 21 e relação de Classe II esquelética. A maxila estava ligeiramente contraída com ausência de mordida cruzada e discrepância de modelo negativa da arcada inferior de 6mm (Fig. 26, 27).

A análise da telerradiografia lateral (Fig. 27B) demonstrou Classe II esquelética $\left(\mathrm{ANB}=6^{\circ}\right)$, padrão vertical de crescimento facial $\left(\mathrm{SnGoGn}=42^{\circ}\right.$ e Eixo Y-SN $=74^{\circ}$ ), incisivos superiores retroinclina$\operatorname{dos}\left(1 . \mathrm{NA}=16^{\circ}\right)$ e em linguoversão $(1-\mathrm{NA}=3 \mathrm{~mm})$ e inferiores projetados e em vestibuloversão (1.NB $=29^{\circ}$ e $1-\mathrm{NB}=5 \mathrm{~mm}$ ), apesar dos mesmos estarem bem implantados na mandíbula $\left(\mathrm{IMPA}=89^{\circ}\right)$. $\mathrm{O}$ perfil se mostrava reto $(\mathrm{S}-\mathrm{LS}=+1 / \mathrm{S}-\mathrm{LI}=+1)$.

Verificou-se, na radiografia panorâmica (Fig. 27A), um posicionamento invertido do elemento 21 intraósseo, com irregularidade na porção radicular sugestiva de dilaceração. $O$ ângulo entre a raiz e a coroa do incisivo central mostrava amplitude de cerca de $90^{\circ}$ na radiografia cefalométrica lateral.

A paciente apresentava hábito prévio de sucção de polegar, causa da mordida aberta anterior manti$\mathrm{da}$, posteriormente, pela postura anterior da língua.

O padrão vertical excessivo, associado à DM negativa seriam fatores decisivos para extrações de quatro pré-molares. Entretanto, a 

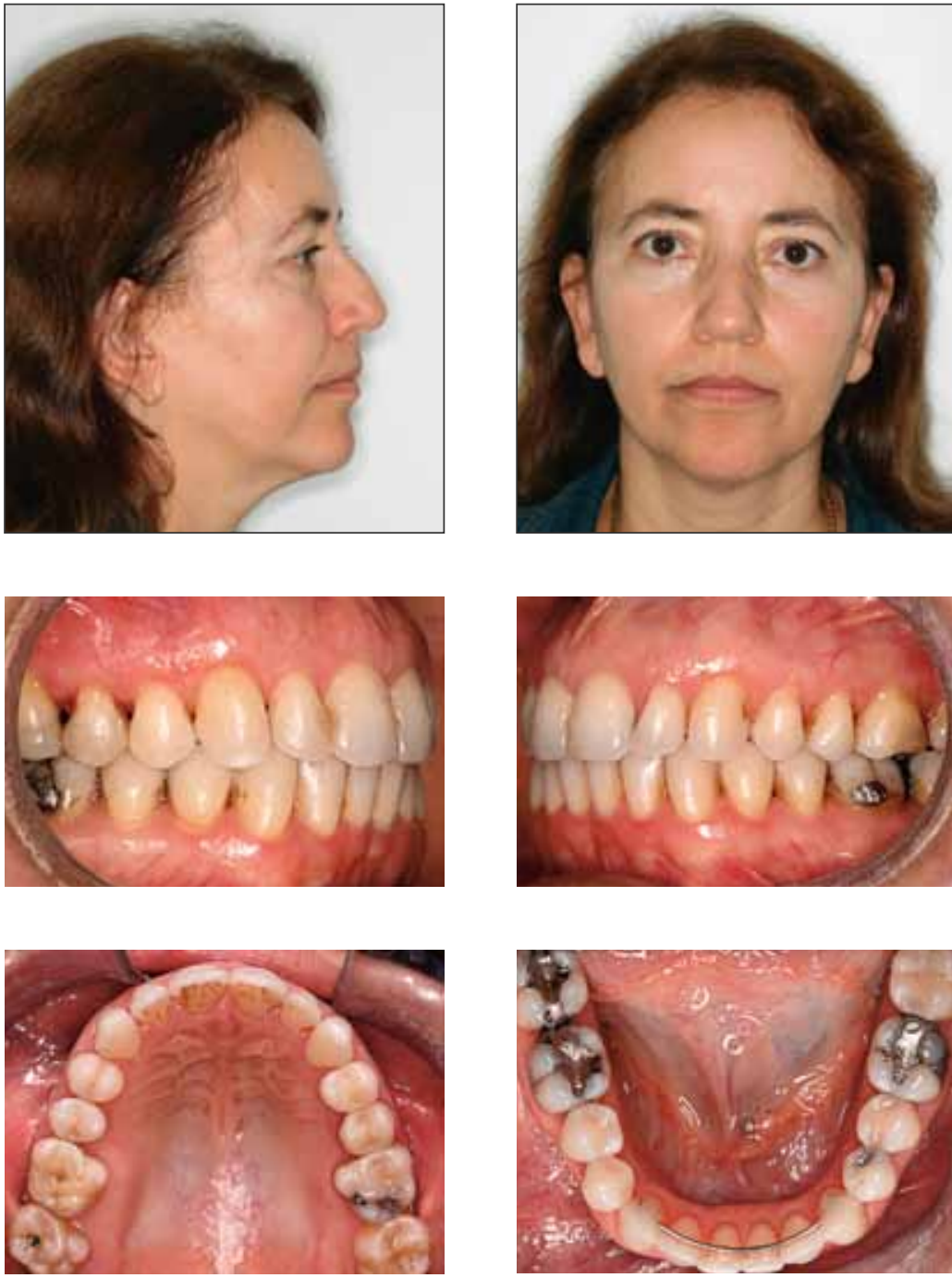

FIGURA 24 - Caso clínico 7: fotografias faciais e intrabucais finais.

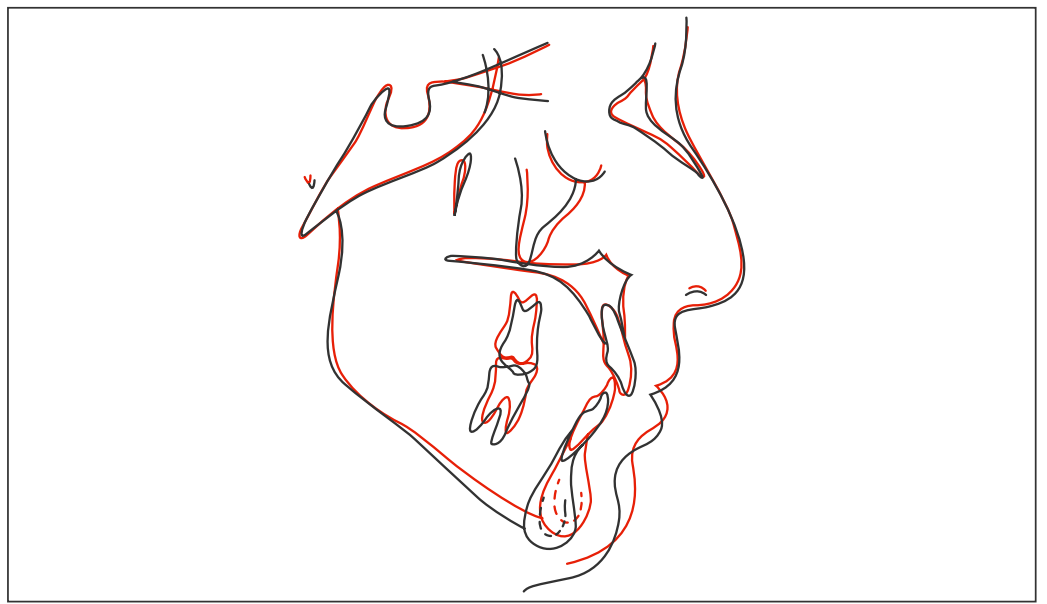

FIGURA 25 - Sobreposição total. 

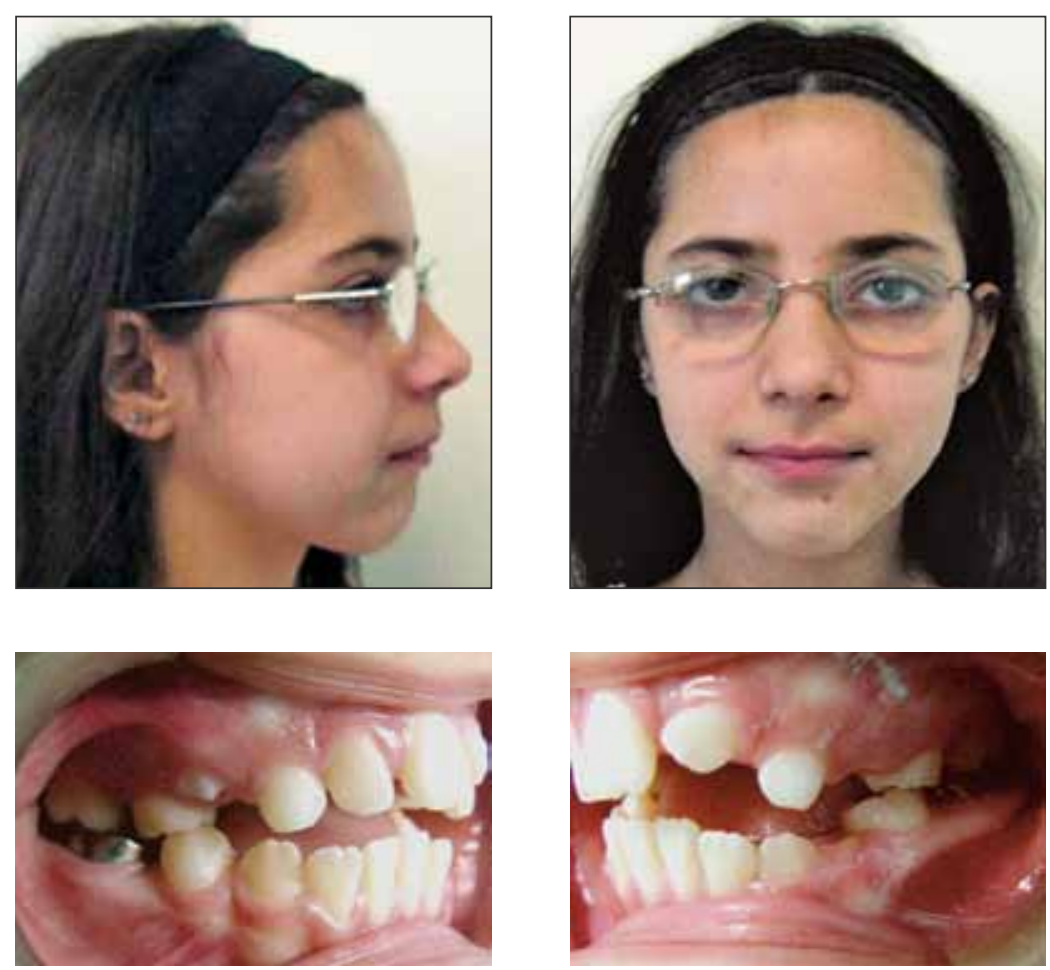

FIGURA 26 - Caso clínico 8: fotografias faciais e intrabucais iniciais.
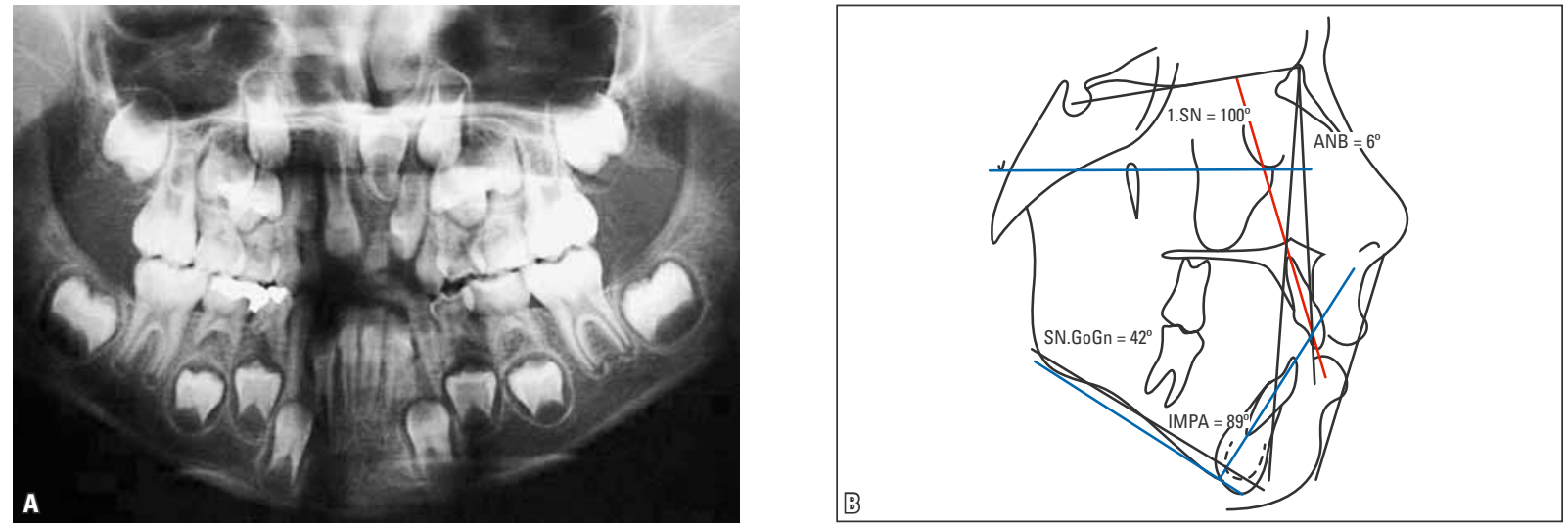

FIGURA 27 - A) Radiografia panorâmica inicial e B) traçado cefalométrico inicial.

patologia (ectopia e dilaceração) do 21 determinou a necessidade de sua extração ao invés do elemento 24. Realizou-se a transposição do elemento 23 para o local do 21. Dessa forma, o caso foi conduzido com extrações dos elementos $14,21,34$ e 44 .

Ao final do tratamento, o padrão vertical da paciente foi mantido (SnGoGn $=40^{\circ}$, Eixo
YSn $=73^{\circ}$ ) às custas das extrações dentárias e da utilização de aparelho extrabucal de tração combinada, minimizando-se, com essa mecânica, o vetor extrusivo. Com o aparelho extrabucal, obteve-se melhor relação anteroposterior das bases ósseas $\left(\mathrm{ANB}=2^{\circ}\right)$, levando a paciente de uma relação de Classe II esquelética para Classe I (Fig. 28, 29). 

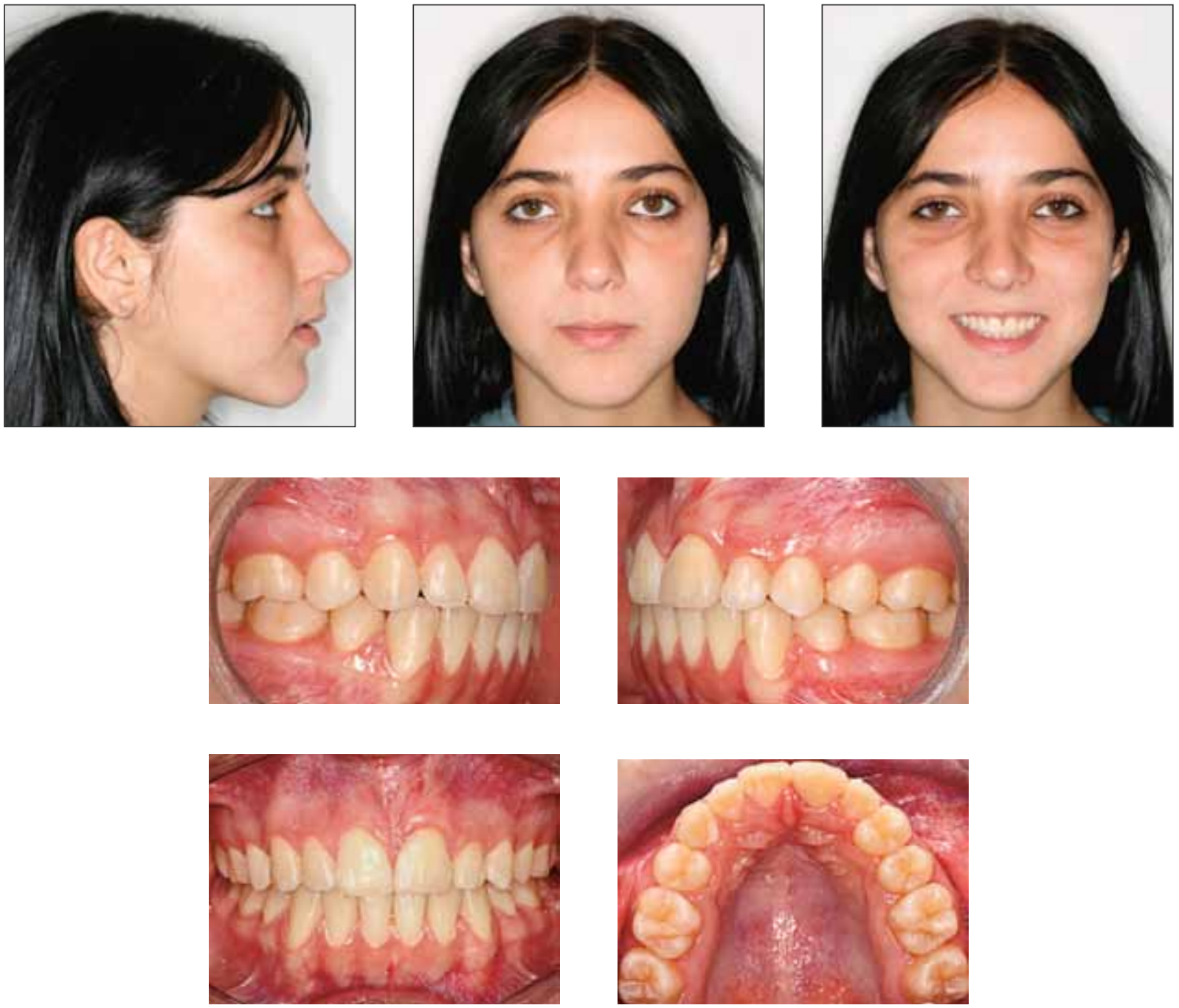

FIGURA 28 - Caso clínico 8: fotografias faciais e intrabucais finais.

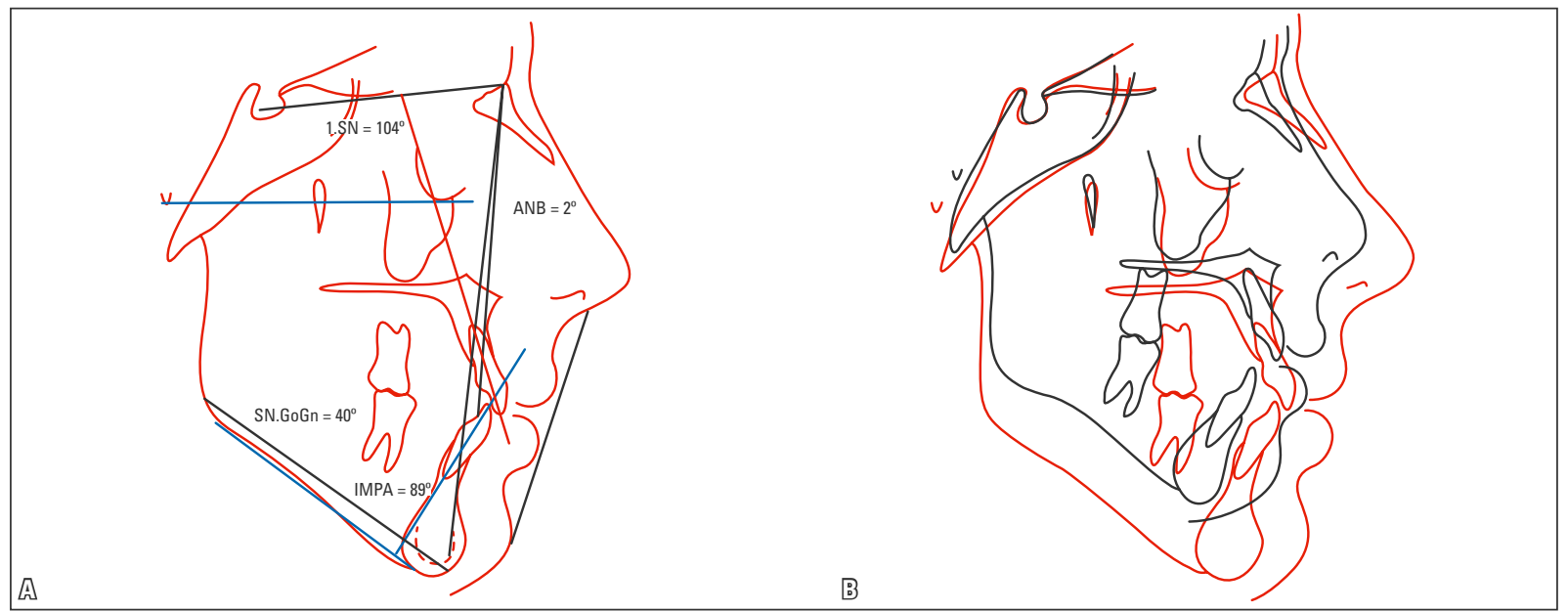

FIGURA 29 - A) Traçado cefalométrico final e B) sobreposição total. 


\section{CONCLUSÃO}

A decisão quanto à necessidade de extrações de dentes durante a terapêutica ortodôntica não está apenas na dependência da falta ou presença de espaços nas arcadas. Outros aspectos devem ser avaliados para se conseguir correção adequada da má oclusão, manutenção ou melhora da estética facial e estabilidade dos resultados obtidos.

\title{
Tooth extraction in orthodontics: an evaluation of diagnostic elements
}

\begin{abstract}
Certain malocclusions require orthodontists to be capable of establishing a diagnosis in order to determine the best approach to treatment. The purpose of this article was to present clinical cases and discuss some diagnostic elements used in drawing up a treatment plan to support tooth extraction. All diagnostic elements have been highlighted: Issues concerning compliance, model discrepancy, cephalometric discrepancy and facial profile, skeletal age (growth) and anteroposterior relationships, dental asymmetry, facial pattern and pathologies. We suggest that sound decision-making is dependent on the factors mentioned above. Sometimes, however, one single characteristic can, by itself, determine a treatment plan.
\end{abstract}

Keywords: Corrective Orthodontics. Diagnosis. Tooth extraction. Orthodontic planning.

\section{REFERÊNCIAS}

1. Aras A. Vertical changes following orthodontic treatment in skeletal open bite subjects. Eur J Orthod. 2002;24(2):407-16.

2. Bernstein L, Edward H. Angle versus Calvin S. Case: extraction versus nonextraction. Historical revisionism. Part II. Am J Orthod Dentofacial Orthop. 1992;102(7):546-61.

3. Boley JC, Pontier JP, Smith S, Fulbright M. Facial changes in extraction and nonextraction patients. Angle Orthod. 1998:68(1):539-46.

4. Burstone CJ. Diagnosis and treatment planning of patients with asymmetries. Semin Orthod. 1998;4(4):153-64.

5. Camargo ES, Mucha JN. Moldagem e modelagem em Ortodontia. Rev Dental Press Ortod Ortop Facial. 1999;4(2):37-50.

6. Chiche GJ, Pinault A. Estética em próteses fixas anteriores. São Paulo: Quintessence; 1996. 202 p.

7. Dewel BF. Second premolar extraction in orthodontics. Principles procedures and case analysis. Am J Orthod. 1955;41(2):107-20.

8. Enlow DH. Crescimento facial. $3^{\mathrm{a}}$ ed. São Paulo: Artes Médicas; 1993. $553 \mathrm{p}$.

9. Fishman LS. Radiographic evaluation of skeletal maturation. A clinically oriented method based on hand-wrist films. Angle Orthod. 1982:52(3):88-112.

10. Hans MG, Groisser G, Damon C, Amberman D, Nelson S, Palomo JM. Cephalometric changes in overbite and vertical facial height after removal of 4 first molars or first premolars. Am J Orthod Dentofacial Orthop. 2006;130(6):183-8.

11. Keedy LR. Indications and contra indications for extraction in orthodontics treatment. Am J Orthod. 1975;68(1):554-63.

12. Kusnoto J, Kusnoto $H$. The effect of anterior tooth retraction on lip position of orthodontically treated adult Indonesians. Am J Orthod Dentofacial Orthop. 2001;120(2):304-7.

13. Lewis P. The deviated midline. Am J Orthod. 1976;70(3):601-18.

14. Massahud NV, Totti JIS. Estudo cefalométrico comparativo das alterações no perfil mole facial pré e pós-tratamento ortodôntico com extrações de pré-molares. J Bras Ortodon Ortop Facial. 2004;9(2):109-19.

15. Moreira TC. A frequência de exodontias em tratamentos ortodônticos realizados na clínica do curso de mestrado em Ortodontia da Faculdade de Odontologia da UFRJ. [dissertação]. Rio de Janeiro: Faculdade de Odontologia da Universidade Federal do Rio de Janeiro, 1993.
16. Proffit WR, Fields JRW. Ortodontia contemporânea. $3^{\mathrm{a}}$ ed. Rio de Janeiro: Guanabara Koogan; 1995.

17. Ramos AL, Sakima MT, Pinto AS, Bowman J. Upper lip changes correlated to maxillary incisor retraction - a metallic implant study. Angle Orthod. 2005;75(3):435-41.

18. Roberts CA, Subtelny JD. Use of the face mask in treatment of maxillary skeletal retrusion. Am J Orthod Dentofacial Orthop. 1988:93(4):388-94

19. Strang RHW. A text-book of Orthodontia. 3rd ed. Philadelphia: Lea \& Febiger; 1950. $825 \mathrm{p}$

20. Talass MF, Tollaae L, Baker RC. Soft-tissue profile changes resulting from retraction of maxillary incisor. Am J Orthod Dentofacial Orthop. 1987;91(7):385-94.

21. Tanaka OM. Avaliação e comparação de métodos de diagnóstico do posicionamento das linhas medianas dentárias no exame clínico e nos modelos em gesso ortodôntico. [tese]. Curitiba: Pontifícia Universidade Católica do Paraná, 2000.

22. Telles CS, Urrea BEE, Barbosa CAT, Jorge EVF, Prietsch JR, Menezes LM, et al. Diferentes extrações em Ortodontia (sinopse). Rev SBO. 1995;2(2):194-9.

23. Vaden JL, Dale JG, Klontz HA. O aparelho tipo Edgewise de Tweed-Merrifield: filosofia, diagnóstico e tratamento. In: Graber TM, Vanarsdall RL. Ortodontia: princípios e técnicas atuais. Rio de Janeiro: Guanabara Koogan; 1996. 897 p.

24. Vilella OV. Manual de cefalometria. Rio de Janeiro: Guanabara Koogan; 1995.

25. Wertz RA. Diagnosis and treatment planning of unilateral Class II malocclusions. Angle Orthod. 1975;45(4):85-94.

26. Williams DR. The effect of different extraction sites upon incisor retraction. Am J Orthod. 1976;69(2):388-410.

Enviado em: março de 2010

Revisado e aceito: abril de 2010

Endereço para correspondência

Antônio Carlos de Oliveira Ruellas

Rua Expedicionários n ${ }^{\circ} 437$, ap. 51 - Centro

CEP: 37.701-041 - Poços de Caldas / MG

Email: antonioruellas@yahoo.com.br 